\title{
Cloud forcing of surface energy balance from in-situ measurements in diverse mountain glacier environments
}

Jonathan P. Conway ${ }^{1}$, Jakob Abermann ${ }^{2,3}$, Liss M. Andreassen ${ }^{4}$, M. Farooq Azam ${ }^{5}$, Nicolas J. Cullen ${ }^{6}$, Noel Fitzpatrick $^{7 \#,}$ Rianne H. Giesen ${ }^{8 *}$, Kirsty Langley ${ }^{3}$, Shelley MacDonell ${ }^{9}$, Thomas Mölg ${ }^{10}$, Valentina 5 Radic $^{7}$, Carleen H. Reijmer ${ }^{8}$, Jean-Emmanuel Sicart ${ }^{11}$.

1 National Institute of Water and Atmospheric Research, Lauder, New Zealand

2 Department of Geography and Regional Science, University of Graz, Graz, Austria

3 Asiaq - Greenland Survey, 3900 Nuuk, Greenland

104 Section for Glaciers, Ice and Snow, Norwegian Water Resources and Energy Directorate (NVE), Oslo, Norway

5 Department of Civil Engineering, Indian Institute of Technology Indore, India-453552

6 School of Geography, University of Otago, Dunedin, New Zealand

7 Earth, Ocean, and Atmospheric Sciences, University of British Columbia, Vancouver, BC, Canada

8 Institute for Marine and Atmospheric research Utrecht (IMAU), Utrecht University, Utrecht, The Netherlands

159 Centro de Estudios Avanzados en Zonas Áridas (CEAZA), Raúl Bitrán 1305, La Serena, Chile

10 Climate System Research Group, Institute of Geography, University Erlangen-Nürnberg (FAU), Germany

11 Univ. Grenoble Alpes, CNRS, IRD, Grenoble-INP, Institut des Géosciences de l'Environnement (IGE, UMR 5001), F38000 Grenoble, France

* now at Royal Netherlands Meteorological Institute (KNMI), De Bilt, The Netherlands

20 \# now at Climate Services and Research Applications Division, Met Éireann, Dublin, Ireland

Correspondence to: Jonathan P. Conway (jono.conway@niwa.co.nz)

\begin{abstract}
Clouds are an important component of the climate system, yet our understanding of how they directly and indirectly affect glacier melt in different climates is incomplete. Here we analyse high-quality datasets from 16 mountain glaciers in diverse climates around the globe to better understand how relationships between clouds and near-surface meteorology, radiation, and surface energy balance vary. The seasonal cycle of cloud frequency varies markedly between mountain glacier sites. During the main melt season at each site, an increase in cloud cover is associated with increased vapour pressure and relative humidity but relationships to wind speed are site-specific. At colder sites (average near-surface air temperature in melt season $<0{ }^{\circ} \mathrm{C}$ ), air temperature generally increases with increasing cloudiness, while for warmer sites (average near-surface air temperature in melt season $\gg 0{ }^{\circ} \mathrm{C}$ ) air temperature decreases with increasing cloudiness. At all sites, surface melt is more frequent in cloudy compared to clear-sky conditions. The proportion of melt from temperature-dependent energy fluxes (incoming longwave radiation, turbulent sensible and latent heat) also universally increases in cloudy conditions. However, cloud cover does not affect daily total melt in a universal way, with some sites showing increased melt energy during cloudy conditions and others decreased melt energy. The complex association of clouds with melt energy is not amenable to simple
\end{abstract}


https://doi.org/10.5194/tc-2022-24

Preprint. Discussion started: 17 February 2022

(c) Author(s) 2022. CC BY 4.0 License.

(c) (i)

35 relationships due to many interacting physical processes (varies with latitude, average melt-season air temperature, continentality, season, and elevation) but is most closely related to the effect of clouds on net radiation. These results motivate the use of physics-based surface energy balance models for representing glacier-climate relationships in regional- and globalscale assessments of glacier response to climate change.

\section{Introduction}

40 Mountain glaciers are sensitive and important components of the climate system. Over the last 50 years, mountain glacier melt has contributed 36-40\% of the observed global sea level rise (Hock et al., 2009; Church et al., 2011; Mernild et al., 2014; Zemp et al., 2019; Hugonnet et al., 2021). During the rest of the $21^{\text {st }}$ century, a large but uncertain fraction of the remaining mass stored in mountain glaciers is expected to melt (Radić et al., 2014; Kraaijenbrink et al., 2017; Marzeion et al., 2018; Huss and Hock, 2018; Zekollari et al., 2019). As glaciers are sensitive to change in their surrounding climate, they can be used to infer past changes in climate over decadal (e.g. Mackintosh et al., 2017), centennial (e.g. Oerlemans, 2005; Mölg et al., 2009b) and paleo-climatic timescales (e.g. Putnam et al., 2012).

Our ability to determine how mountain glacier melt responds to changes in climate depends on the ability of models to correctly represent the processes that occur at the atmosphere-glacier interface and link near-surface meteorology and surface melt. The surface energy balance (SEB) is the key process that controls the rate of melt at the glacier surface and can be represented as:

$Q_{M}=S W n e t+L W n e t+Q_{S}+Q_{L}+Q_{C}+Q_{P R C}$

where $Q_{M}$ is the energy available for melt (zero when surface is freezing), SWnet and LWnet are the net fluxes of short and long-wave radiation (including shortwave radiation that penetrates the surface), $Q_{S}$ and $Q_{L}$ are the turbulent fluxes of sensible and latent heat, $Q_{C}$ is the conductive heat flux into/out of the glacier subsurface and $Q_{P R C}$ is the heat advected from precipitation. Fluxes on the righthand side of Equation 1 are defined as positive towards the surface. When the surface is at the melting point, $Q_{M}$ becomes non-zero and positive, and surface melt ( $M$, mm w.e.) is determined through:

where $\Delta t$ is the timestep of model output (seconds) and $L_{f}$ is the latent heat of fusion $\left(3.34 \times 10^{5} \mathrm{~J} \mathrm{~kg}^{-1}\right)$. In many studies, these relationships between near-surface meteorology and melt are simplified into parameterisations that require less input data such as temperature index or enhanced temperature index melt models (Huybrechts and Oerlemans, 1990; Hock, 2003; Pellicciotti

65 et al., 2005) 
While we know that glaciers are sensitive to changes in local climate, the extent to which cloud cover will amplify or reduce the melting of a glacier in response to future atmospheric warming is uncertain. Clouds alter the incoming shortwave (SWin) and longwave (LWin) radiation, which are generally the largest sources of energy at the glacier surface (Sicart et al., 2008;

70 Pellicciotti et al., 2011; Van Den Broeke et al., 2011; Cullen and Conway, 2015). Over highly reflective glacier surfaces, a 'radiation paradox' can occur, where net radiation (Rnet) increases during cloudy conditions (Ambach, 1974). Clouds can also enhance or dampen the influence of near-surface meteorology, albedo feedbacks and subsurface processes (e.g. refreezing) on SEB and melt (Giesen et al., 2008; Giesen et al., 2014; Conway and Cullen, 2016; Van Tricht et al., 2016). As a result, clouds have been associated with both increased and decreased melt rate depending on the climate (Van Den Broeke et al., 2011;

75 Conway and Cullen, 2016; Chen et al., 2021). In the maritime Southern Alps of New Zealand, cloudy conditions have been shown to increase the sensitivity of melt to changes in air temperature (Conway and Cullen, 2016), due to: (i) more frequent melt in cloudy compared to clear-sky conditions, (ii) increased (positive) LWnet and $Q_{L}$ in cloudy conditions that enable a similar daily melt rate as clear-sky conditions, and (iii) a change in precipitation phase (from snow to rain) that enhances a positive snowdepth - albedo feedback. The higher sensitivity in cloudy conditions implies that, in the Southern Alps, the response of glacier melt (as well as accumulation) to past and future atmospheric warming will be modulated by atmospheric moisture (in the form of vapour/cloud/precipitation). How these processes interact in different mountain glacier environments and climate regimes has not been well established.

One challenge has been the lack of direct measurements of cloud amount or type (from e.g. human observer, all-sky camera, 85 or ceilometer) in mountain areas, which has required the derivation of cloud metrics from surface radiation measurements. Studies have employed a variety of methods to derive cloudiness from surface radiation measurements, which limits the ability to directly compare results from studies in different regions (Giesen et al., 2008; Conway and Cullen, 2016; Sicart et al., 2016; Chen et al., 2021).

90 The key question of this paper is, therefore: how does cloudiness and its relationships with near-surface meteorology, radiation, and energy balance vary in different mountain glacier environments? The objective is to use a common framework to assess these relationships at a diverse set of sites where high-quality observations and modelling are available. To guide the analyses, a set of questions was posed:

i. How often do different cloud conditions occur at each site?

95 ii. What is the direct effect of clouds on surface radiation at each site?

iii. How does near-surface meteorology vary with cloudiness?

iv. How do the characteristics of melt (e.g. frequency, amount and source of energy) vary in different cloud conditions?

Section 2 sets out the methods used to collate and analyse data sets from 16 glacier AWS sites, including the calculation of cloudiness from LWin, the definition of melting periods and melt season, and analysis of cloud effects. Section 3 presents 
https://doi.org/10.5194/tc-2022-24

Preprint. Discussion started: 17 February 2022

(c) Author(s) 2022. CC BY 4.0 License.

(c) (i)

results that address the four questions posed above. Section 4 discusses commonalities and differences in cloud - meteorology - SEB - melt relationships, uncertainties and implications for glacier melt modelling.

\section{Methods}

\subsection{Sites and dataset requirements}

105 Datasets of near-surface meteorology and glacier surface energy balance were collated from a diverse set of sites where highquality observations and modelling were available. The sites were required to have a published SEB record calculated from automatic weather station (AWS) data collected over a glacier surface during melt seasons at hourly or smaller timestep. The AWS data needed to include measurements of all four components of the radiation balance, incoming (SWin) and outgoing shortwave (SWout), incoming (LWin) and outgoing longwave (LWout), all in $\mathrm{W} \mathrm{m}^{-2}$. In addition, other SEB components needed to be calculated using accepted best-practice methods (e.g. turbulent fluxes calculated using bulk aerodynamic methods) and avoiding potentially inaccurate assumptions (e.g. surface temperature fixed at $0{ }^{\circ} \mathrm{C}$ regardless of SEB). Note that published values of surface melt and SEB fluxes are used in these analyses rather than being recalculated from near-surface meteorology and radiation. Thus, differences in the methods used to calculate SEB may introduce some uncertainty, but the values are congruent with previous studies, and no additional validation is needed. A call for datasets was made on Cryolist in January

1152020 , and data from over 30 sites was offered. After assessing each dataset against the criteria above, 16 sites were selected for analysis (Figure 1 and Table 1). These sites covered many of the mountain glacier regions including continental North America, the European Alps, Norway, Greenland, the Himalaya, tropical glaciers in Africa and the Andes, the arid region of central Chile and the Southern Alps of New Zealand. It is worth noting that no suitable datasets were made available from some large regions of mountain glaciers including Alaska, Patagonia and Asia outside of the Himalaya.

120

As most AWS sites are in ablation areas, they follow a broad pattern of decreasing altitude with distance from the equator (Figure 2). Note that two locations have observations in both the ablation and accumulation area - Conrad Glacier (CABL, CACC) and Mera Summit (MERA) / Naulek (NAUL, an ablation area of Mera Glacier). Records from the same site in different years were also joined into continuous records (CABL and NAUL). Records from CABL, CACC and NORD cover only

125 summer periods and CHHO has three two-month periods throughout the year, otherwise the records span all months of the year and range from 46 to 3231 days in length. 
https://doi.org/10.5194/tc-2022-24

Preprint. Discussion started: 17 February 2022

(c) Author(s) 2022. CC BY 4.0 License.

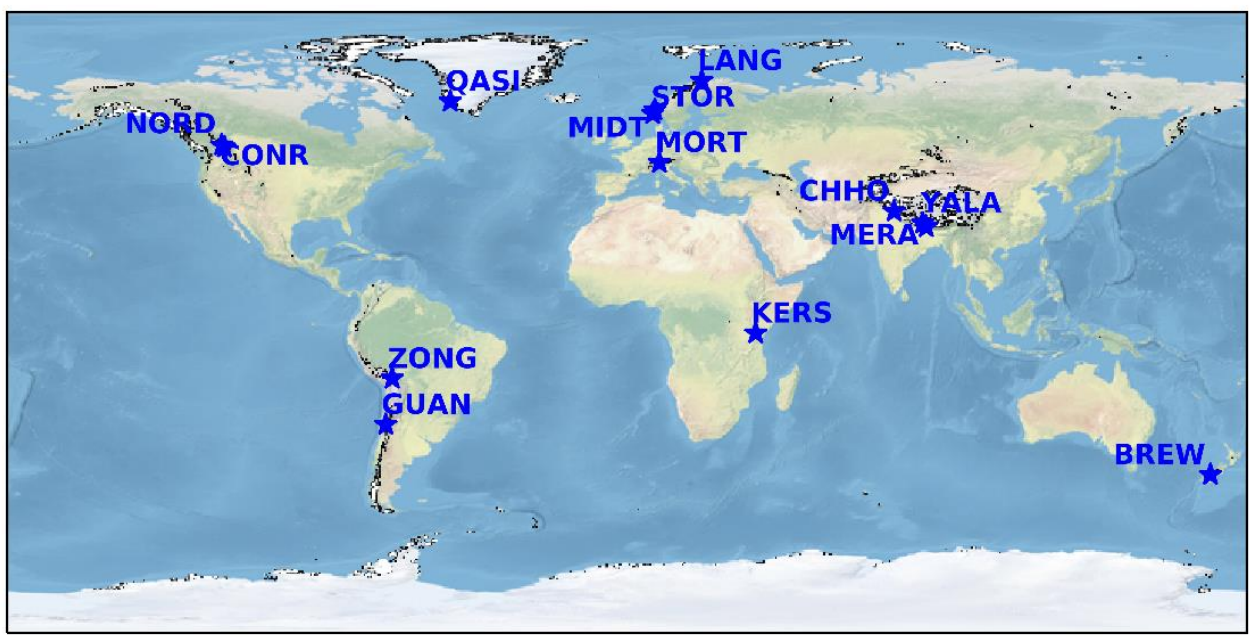

130 Figure 1: Map showing location of study sites with short names (See Table 1 for full names) along with glacier areas from the Randolph Glacier inventory (black outlines). Note the two Conrad Glacier sites (CABL, CACC) are shown as CONR and the two Mera Glacier sites (MERA, NAUL) as MERA.

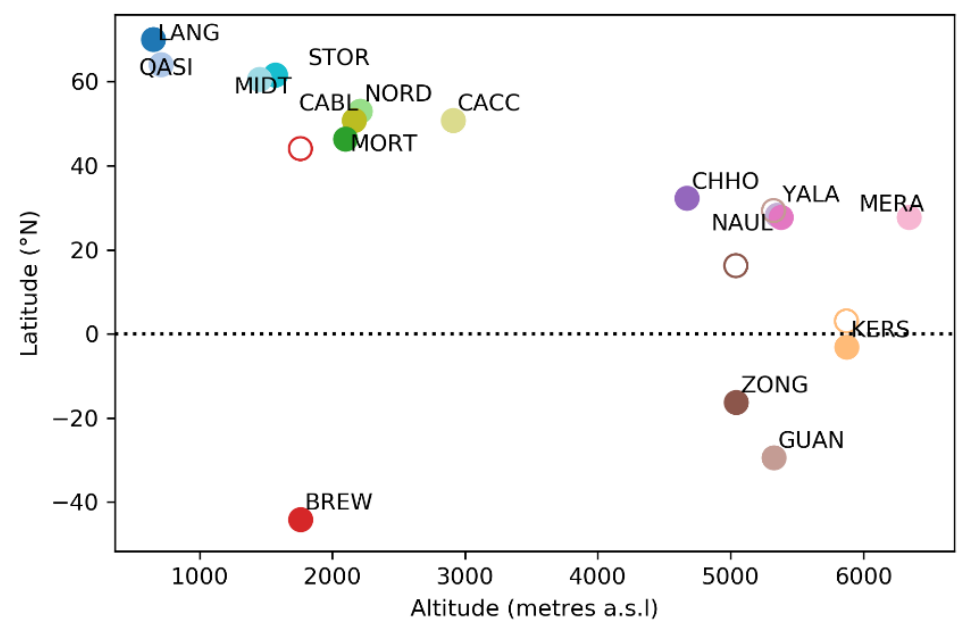

135 Figure 2: Altitude and latitude of study sites. Open circles show the position of southern hemisphere sites against northern hemisphere sites for comparison. 
https://doi.org/10.5194/tc-2022-24

Preprint. Discussion started: 17 February 2022

(c) Author(s) 2022. CC BY 4.0 License.

(c) (i)

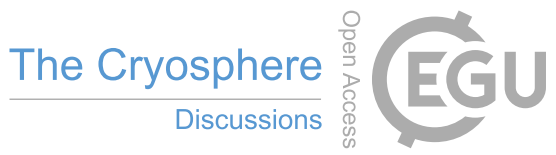

Table 1: Details of study sites listed by latitude

\begin{tabular}{|c|c|c|c|c|c|c|c|c|}
\hline Name & $\begin{array}{l}\text { Short } \\
\text { name }\end{array}$ & $\begin{array}{l}\text { Latitude } \\
\qquad\left({ }^{\circ} \mathrm{N}\right)\end{array}$ & $\begin{array}{l}\text { Longitude } \\
\qquad\left({ }^{\circ} \mathrm{E}\right)\end{array}$ & $\begin{array}{l}\text { Altitude } \\
\text { (m) }\end{array}$ & $\begin{array}{c}\text { Country } \\
\text { code } \\
\text { (ISO } \\
3166)\end{array}$ & $\begin{array}{l}\text { Record } \\
\text { length } \\
\text { (days) }\end{array}$ & $\begin{array}{l}\text { Years of } \\
\text { record }\end{array}$ & Reference \\
\hline Langfjordjøkelen & LANG & 70.133 & 21.75 & 650 & NO & 1070 & $2007-10$ & Giesen et al. (2014) \\
\hline Qasigiannguit & QASI & 64.162 & -51.359 & 710 & $\mathrm{GL}$ & 703 & $2014-16$ & Abermann et al. (2019) \\
\hline Storbreen & STOR & 61.583 & 8.166 & 1570 & NO & 1827 & 2001-06 & $\begin{array}{l}\text { Andreassen et al. (2008); } \\
\text { Giesen et al. (2009) }\end{array}$ \\
\hline Midtdalsbreen & MIDT & 60.567 & 7.467 & 1450 & NO & 2137 & $2000-06$ & $\begin{array}{c}\text { Giesen et al. (2008); Giesen et } \\
\text { al. (2009) }\end{array}$ \\
\hline Nordic & NORD & 53.051 & -120.444 & 2208 & $\mathrm{CA}$ & 46 & 2014 & Fitzpatrick et al. (2017) \\
\hline Conrad (ablation) & CABL & 50.823 & -116.920 & 2164 & $\mathrm{CA}$ & 119 & $2015-16$ & Fitzpatrick et al. (2019) \\
\hline Conrad (accum) & CACC & 50.782 & -116.912 & 2909 & $\mathrm{CA}$ & 68 & 2016 & Fitzpatrick et al. (2019) \\
\hline Morteratsch & MORT & 46.422 & 9.9318 & 2100 & $\mathrm{CH}$ & 3231 & $\begin{array}{l}1998- \\
2007\end{array}$ & Oerlemans et al. (2009) \\
\hline Chhota Shigri & $\mathrm{CHHO}$ & 32.28 & 77.58 & 4670 & IN & 177 & $2012-13$ & Azam et al. (2014) \\
\hline Yala & YALA & 28.235 & 85.618 & 5350 & NP & 811 & $2014-18$ & Litt et al. (2019) \\
\hline Mera Summit & MERA & 27.706 & 86.874 & 6342 & NP & 867 & 2013-16 & Litt et al. (2019) \\
\hline Naulek (Mera) & NAUL & 27.718 & 86.897 & 5380 & NP & 1387 & 2013-17 & Litt et al. (2019) \\
\hline Kersten & KERS & -3.078 & 37.354 & 5873 & $\mathrm{TZ}$ & 1078 & $2005-08$ & Mölg et al. (2009b) \\
\hline Zongo & ZONG & -16.25 & -68.167 & 5040 & $\mathrm{BO}$ & 362 & $\begin{array}{l}1999- \\
2000\end{array}$ & Sicart et al. (2005) \\
\hline Guanaco & GUAN & -29.34 & -70.01 & 5324 & $\mathrm{CL}$ & 910 & $2008-11$ & MacDonell et al. (2013) \\
\hline Brewster & BREW & -44.08 & 169.43 & 1760 & NZ & 676 & $2010-12$ & $\begin{array}{l}\text { Conway and Cullen (2016); } \\
\text { Cullen et al. (2016) }\end{array}$ \\
\hline
\end{tabular}

140

\subsection{Data processing}

Data from each site were taken through several processing steps as outlined in Figure 3. After basic quality control and homogenisation (described below), a timeseries of cloudiness was generated for each site (Section 2.3), melting periods and the main melt season were defined (Section 2.4), after which cloud effects on melt were analysed (Section 2.5). 


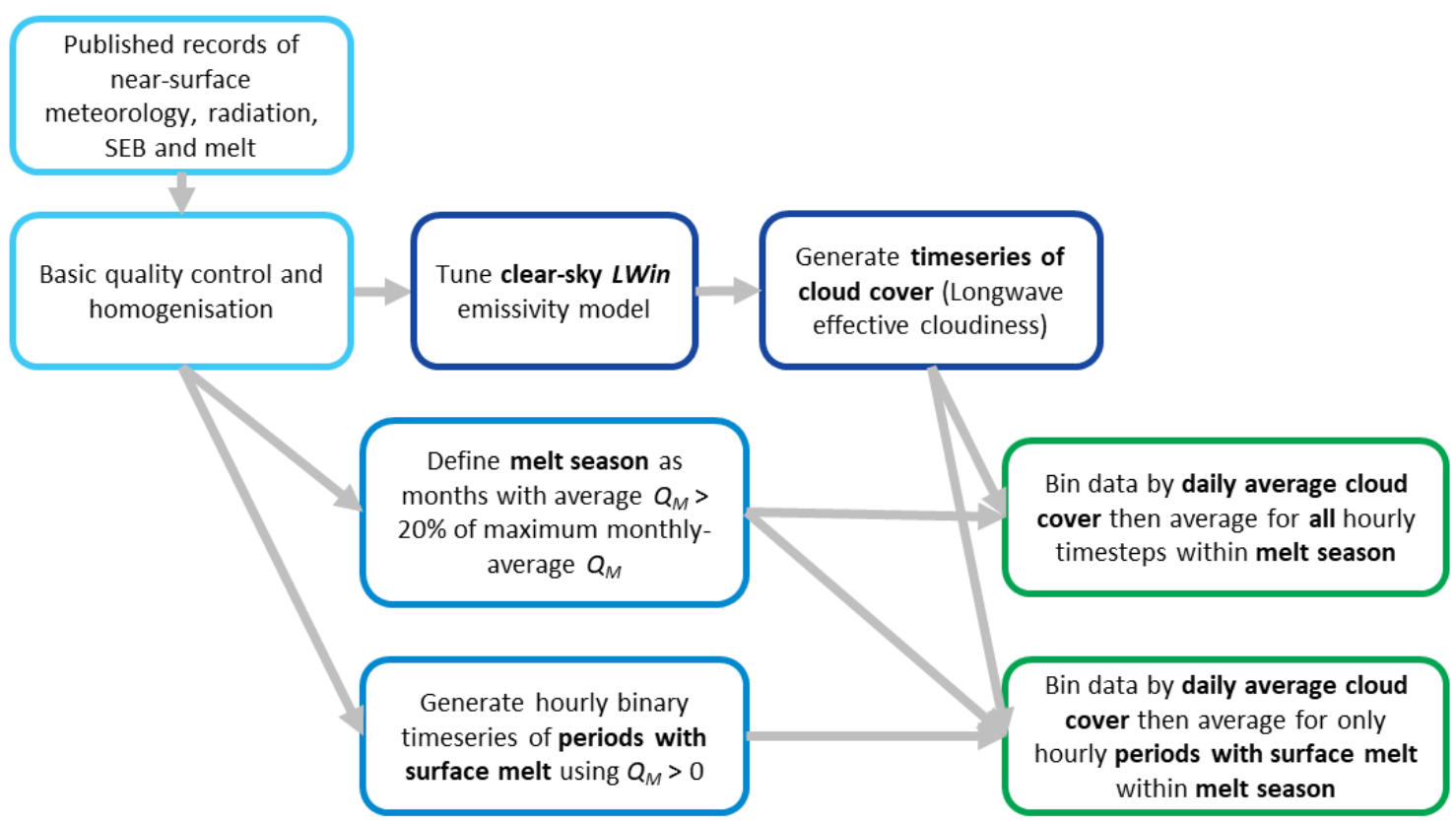

Figure 3: Step used to process and analyse data.

Basic quality control and homogenisation involved the following steps:

- Sub-hourly data resampled to hourly time steps

- Times converted to local solar time using longitude rounded to nearest full hour offset from UTC.

- Data cut to full days only (no days with partial missing data)

- Naming, units and sign conventions of variables standardised

- Periods with missing radiation data (SWin, SWout, LWin, LWout) removed

- $\quad$ Periods with missing near-surface air-temperature $\left(T_{a} ;{ }^{\circ} \mathrm{C}\right)$ or relative humidity $(R H)$ data removed.

- $\quad$ Negative values of SWin and SWout set to 0

- Values of LWout $>315.6 \mathrm{~W} \mathrm{~m}^{-2}$ reset to $315.6 \mathrm{~W} \mathrm{~m}^{-2}$

- $\quad$ Net radiation (Rnet) calculated from corrected values of (SWin, SWout, LWin, LWout)

- $\quad$ Near-surface vapour pressure $\left(e_{a} ; \mathrm{hPa}\right)$ calculated from $T_{a}$ and $R H$ using Buck (1981)

- Surface temperature $\left(T_{s} ;{ }^{\circ} \mathrm{C}\right)$ calculated from $L W o u t$ if not provided

- Daily average albedo calculated as ratio of daily sums of SWin and SWout

- If $Q_{M}$ or surface melt calculated from SEB model is not provided, then $Q_{M}$ is calculated as positive values of SEB when $T_{s}>-0.1^{\circ} \mathrm{C}$

Monthly statistics (averages, frequencies by bin etc.) were only calculated when at least 10 days of data from a given month were available. Figures A1 and A2 show monthly average meteorology and SEB fluxes for each site used in the analysis. 
https://doi.org/10.5194/tc-2022-24

Preprint. Discussion started: 17 February 2022

(c) Author(s) 2022. CC BY 4.0 License.

(c) (i)

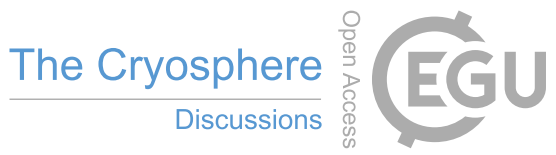

\subsection{Defining clear-sky and cloudy periods using incoming longwave radiation}

For each site, timeseries of cloudiness were derived from measured $L$ Win, $e_{a}$ and near-surface air temperature $\left(T_{a, K} ; \mathrm{K}\right)$. First, the effective sky emissivity $\left(\varepsilon_{e f f}\right)$ was calculated using:

$170 \varepsilon_{\text {eff }}=\operatorname{LWin} / \sigma T_{a, K}{ }^{4}$

While LWin is influenced by emission from surrounding terrain, the sky-view factor at all sites is close to 1 and horizons at all sites are below the limit of the sensor field of view, so no corrections were needed here.

175 Timeseries of theoretical clear-sky emissivity $\left(\varepsilon_{c s}\right)$ at each site were defined using the Brutsaert (1975) curve as modified by Konzelmann (1994) with the exponent set to 1/7 after Dürr et al. (2006):

$\varepsilon_{c s}=\varepsilon_{a d}+b\left(100 \times e_{a} / T_{a, K}\right)^{(1 / 7)}$

180 where $\varepsilon_{a d}$ is an elevation-dependent dry air emissivity term (varying between 0.18 and 0.23 ) defined here using $\varepsilon_{a d}$ values determined from radiative transfer modelling in Durr et al. (2006) for the European Alps that are regressed against elevation ( $z ; \mathrm{m}$ above sea level):

$\varepsilon_{a d}=0.2351-z \times 9.636 \times 10^{-6}$

185

For each site, Equation 4 was fitted to the lowest $10 \%$ of $L$ Win in $30 e_{a} / T_{a . K}$ bins (Figure A3) by finding the value of $b$ (in 0.001 steps) that gave the smallest root mean square error (RMSE). This step used only hours with valid $L W i n, e_{a}$ and $T_{a . K}$ values and $R H<80 \%$. Optimised values of $b$ and RMSE are given in Table A1.

190 Timeseries of longwave equivalent cloudiness $\left(N_{\varepsilon}\right)$ were then derived by fitting hourly measured $\varepsilon_{e f f}$ between theoretical clearsky $\left(\varepsilon_{c s}\right)$ and overcast $\left(\varepsilon_{o v}=1\right)$ emissivity values, limiting $N_{\varepsilon}$ to a range 0 to 1 (Conway et al., 2015):

$N_{\varepsilon}=\left(\varepsilon_{\text {eff }}-\varepsilon_{c S}\right) /\left(\varepsilon_{o v}-\varepsilon_{c S}\right) ;$

$N_{\varepsilon}\left[N_{\varepsilon}>1\right]=1 ; N_{\varepsilon}\left[N_{\varepsilon}<0\right]=0$

Following Giesen et al. (2008), clear-sky conditions are defined as $N_{\varepsilon}<=0.2$, partly cloudy as $0.2>N_{\varepsilon}>0.8$ and overcast as $N_{\varepsilon}>=0.8$. Daily average, rather than hourly average, $N_{\varepsilon}$ was used to define cloudiness to reduce noise, limit the influence of diurnal cycles in variables and focus on synoptic scale (daily) variability in cloud - SEB relationships. Note that moderate 
values of daily average cloudiness can indicate either patchy cloud cover and/or a mix of overcast and clear-sky conditions during a day. Cloudiness can be derived from SWin (e.g. Greuell et al., 1997; Sicart et al., 2006; Mölg et al., 2009a; Kuipers Munneke et al., 2011) but was considered a less appropriate metric here as its calculation relies onsetting a typical cloud extinction coefficient that differs between sites (Pellicciotti et al., 2011). In addition, shading of SWin introduces further uncertainty, especially in winter and SWin does not provide meaningful values during the night time.

\subsection{Definition of melt season and periods with surface melt}

205 For each site, a melt season was defined as the months in which monthly-average $Q_{M}$ at the site was greater than $20 \%$ of the maximum monthly-average $Q_{M}$ for the same site (Figure A2; A4). This proved a simple method to retain months with substantial melt but exclude winter months where melt is infrequent. The sensitivity of this choice was assessed by replicating key results using only months with monthly-average $Q_{M}$ greater than $80 \%$ of the maximum monthly-average $Q_{M}$ for that site. Rather than only selecting individual melt events for analysis, averages over all timesteps in the melt season were used to better understand the relationships between cloudiness, surface radiation and near-surface meteorology, without skewing the data towards melt episodes that may have atypical meteorology. To identify the times surface melt occurred and to quantify the contributions of SEB components to $Q_{M}$, periods with surface melt were defined as hourly timesteps with $Q_{M}>0$.

\subsection{Analysis of cloud effects}

215 The relationship between cloudiness, meteorology, SEB and melt is assessed by binning the timeseries of different variables by daily average cloudiness. Five evenly sized bins were used with bin centres at $N_{\varepsilon}=0.1,0.3,0.5,0.7$ and 0.9 , with the top and bottom bins corresponding to clear-sky and overcast conditions, respectively. Data within each bin were then averaged across all days within the main melt season to demonstrate the average relationships between cloudiness and different variables.

220 In sections 3.2, 3.3 and 3.4, we use the term cloud effects to describe the change in a variable during cloudy conditions with respect to clear-sky conditions. In studies of net radiation, the cloud effect (CE) is defined as the difference between average and clear-sky conditions. Here we extend the concept to $Q_{M}$ in order to describe the average change in melt related to clouds, even though clouds are not the only meteorological forcing responsible for changes in $Q_{M}$. We calculate $\mathrm{CE}$ for all net radiation components (SWnet, LWnet, Rnet) and $Q_{M}$. Here, we calculate CE by subtracting the average value in the clear-sky bin $\left(N_{\varepsilon}<=\right.$ 2250.2 ) from the average value equally weighted across all cloudiness bins. Equally weighting each cloudiness bin ensures that differences in the frequency of different cloud conditions do not skew the data between sites. 
https://doi.org/10.5194/tc-2022-24

Preprint. Discussion started: 17 February 2022

(c) Author(s) 2022. CC BY 4.0 License.

(c) (i)

\section{Results}

\subsection{Cloud metrics}

\subsubsection{Effective sky emissivity and fitted clear-sky curve}

230 The derivation of clear-sky emissivity from LWin highlighted substantial variations in the relationship between near-surface meteorology and LWin between the sites. On an hourly basis, most sites show a preference for either clear-sky or overcast conditions, as shown by the darker colours around the clear-sky and overcast emissivity (Figure 4). Sites in the Himalaya (CHHO, YALA, NAUL, MERA) showed a distinct seasonality with predominately warm/wet/overcast or cold/dry/clear-sky conditions. Tropical and arid glacier sites (KERS, GUAN) show a much lower $\varepsilon_{c s}$ for the same surface vapour pressure, in part

235 due to the high elevation (therefore low $\varepsilon_{a d}$ ), but also due to the low value of $b$ (Equation 4; Table A1), which indicates a thinner atmospheric water vapour profile above the surface compared to Himalayan sites at similar altitudes. Mid-latitude sites with records covering the full annual cycle in Europe (LANG, MIDT, MORT, STOR) and New Zealand (BREW) show a similar preference for cold/dry/clear-sky or warm/wet/overcast conditions, while QASI shows a greater frequency of cloud at lower temperature/vapour pressure. Sites in the Western Cordillera of Canada (NORD, CABL, CACC) and Europe (MIDT,

240 MORT, STOR) show more frequent partial cloud than many other sites. Note that the short summertime records from Canada (NORD, CABL, CACC) do not capture the full spectrum of conditions at these sites. 

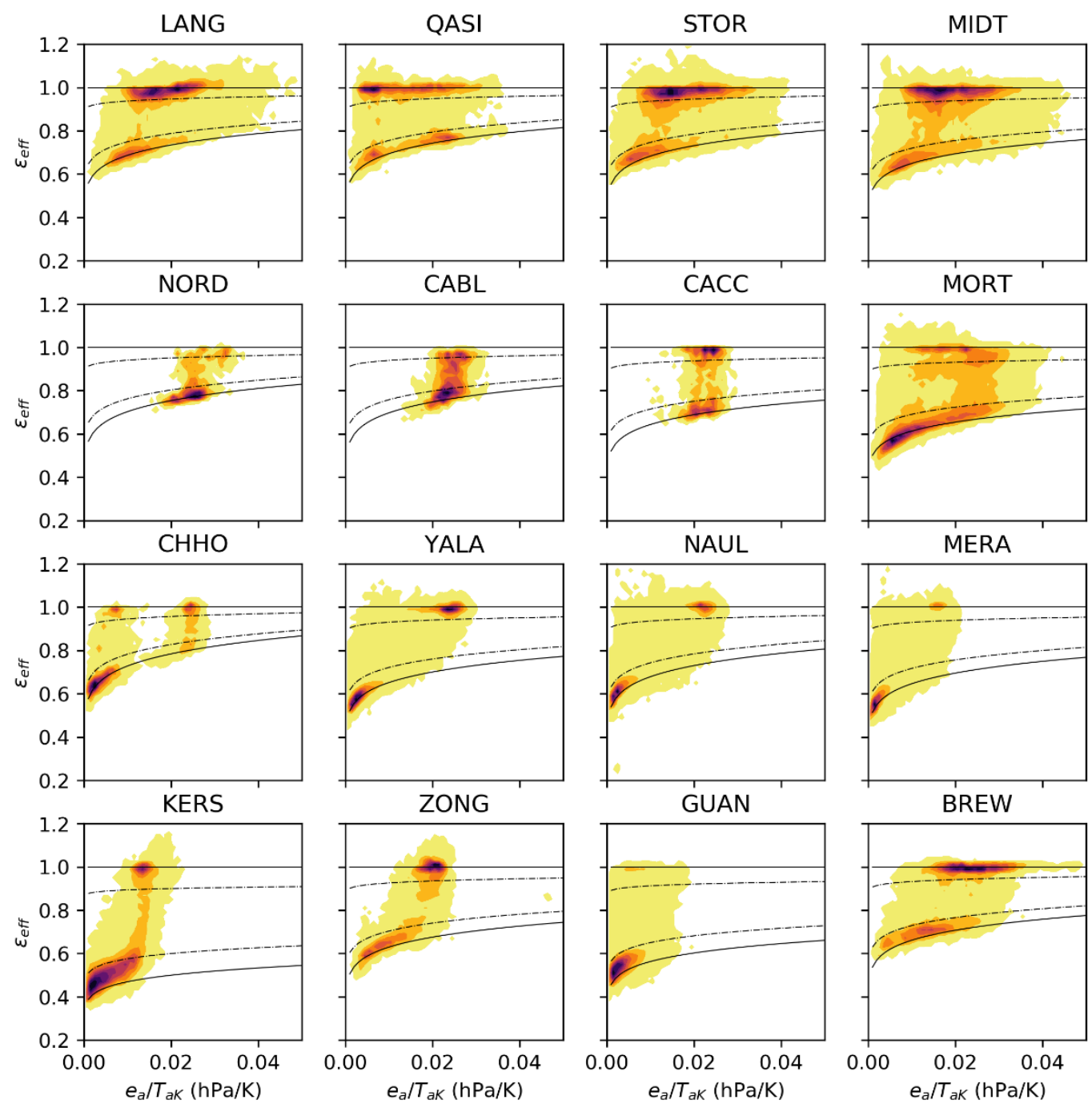

Figure 4: Observed $\varepsilon_{e f f}$ (filled contours) versus $e_{a} / T_{a, K}$ for sites arranged by latitude. Also shown are calculated $\varepsilon_{c s}$ (lower solid line) $\varepsilon_{o v}$ (upper solid line) and $\varepsilon_{e f f}$ at clear-sky and overcast limits of $N_{\varepsilon}=0.2$ and $N_{\varepsilon}=0.8$, respectively (lower and upper dashed lines, respectively). Contours created from $2 D$ histogram with common $x$ and $y$ bins across all sites with colours in 10 steps between 1 and the maximum number of hours in any $x, y$ bin for each site.

\subsubsection{Monthly cloud frequency}

250 The frequency of clear-sky, partial-cloud and overcast conditions also shows distinct regional and seasonal variations (Figure 5 for daily average, Figure A4 for hourly periods). Mid-latitude glaciers in maritime locations show very limited seasonality (BREW, STOR, MIDT) and a high percentage of overcast conditions, except for LANG that displays more frequent overcast conditions during the melt season and QASI that shows a tendency towards more frequent clear-sky conditions during its melt 
https://doi.org/10.5194/tc-2022-24

Preprint. Discussion started: 17 February 2022

(c) Author(s) 2022. CC BY 4.0 License.

(c) (i)

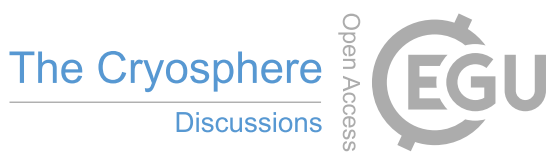

season. Mid-latitude sites in continental locations (NORD, CABL, CACC, MORT) show less frequent overcast and more 255 frequent partial-cloud conditions than the mid-latitude maritime sites, with MORT showing more frequent partial-cloud conditions during the melt season and more frequent clear-sky conditions in the winter. Most Himalayan sites (YALA, MERA, NAUL) show much stronger seasonality, with more frequent overcast conditions during the melt season, except CHHO, which shows weaker monsoon influence (fewer overcast conditions) being on the transition zone between monsoon and arid regions. While ZONG experiences melt most of the year, melt rates are higher during the cloudier months from September through 260 April corresponding with marked seasonal changes in cloud and SEB caused by the tropical climate (Figure A2). KERS experiences less cloud from June through October, with low melt rates year-round. GUAN experiences the least cloud, with predominately clear-sky conditions and only sporadic melt during austral summer. 
https://doi.org/10.5194/tc-2022-24

Preprint. Discussion started: 17 February 2022

(c) Author(s) 2022. CC BY 4.0 License.
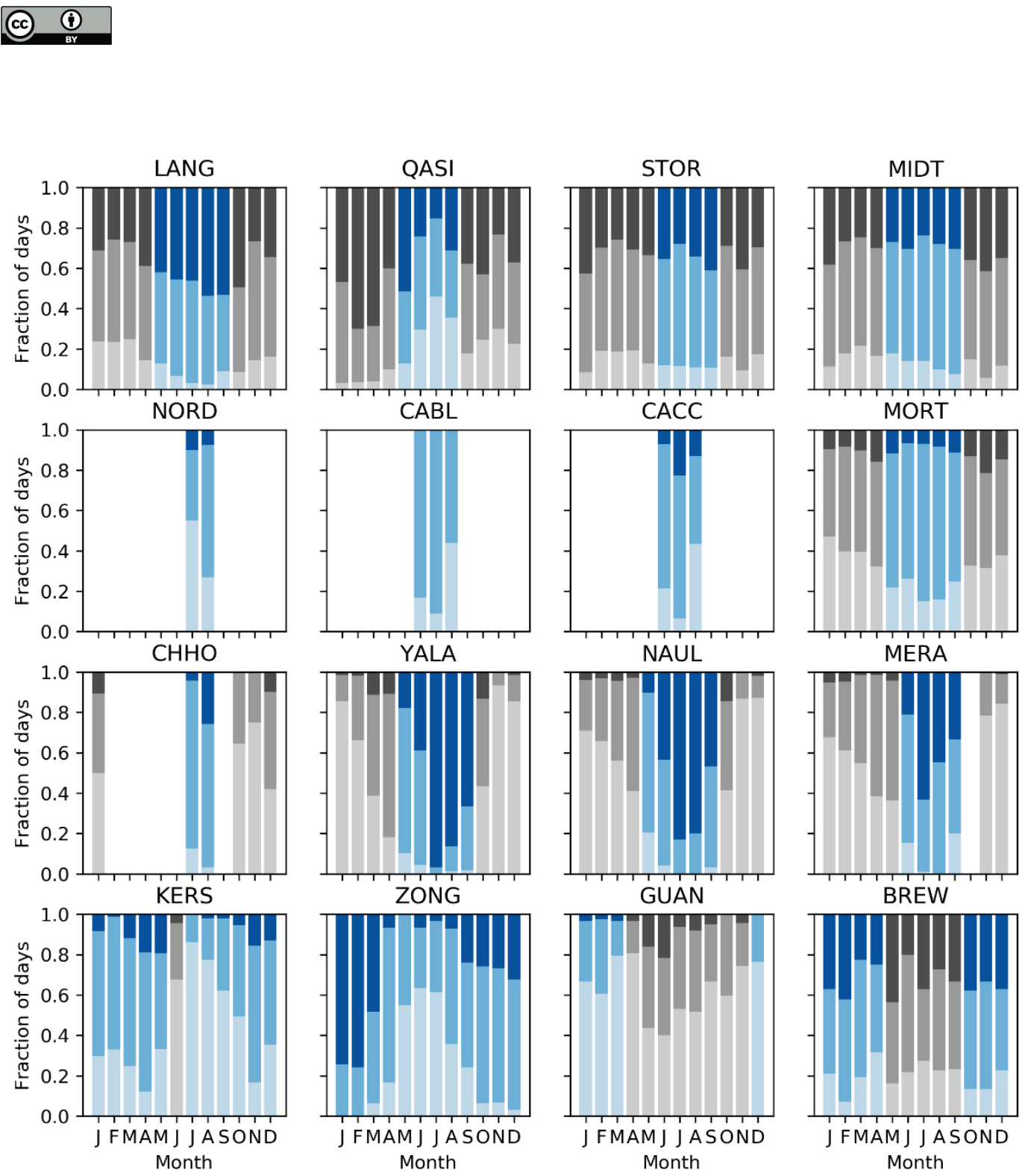

Figure 5: Monthly fraction of clear-sky (light shading), partial-cloud (mid shading) and overcast conditions (dark shading) defined using daily average cloudiness $\left(N_{\varepsilon}\right)$. Months defined as within the 'melt season' are shaded blue.

\subsection{Cloud effects on melt-season surface radiation}

An estimate of the direct effect of clouds on the SEB is gained by examining the variation of incoming radiation (SWin and

LWin) with cloudiness (Figure 6). At most sites the average direct effect of clouds on incoming radiation is negative, steadily decreasing with increasing cloud cover to between -60 and $-170 \mathrm{~W} \mathrm{~m}^{-2}$ (Figure 6f). The exceptions are low-latitude and highaltitude sites KERS, MERA, and ZONG, where comparatively small decreases in SWin with cloudiness (Figure 6d) are compensated by large increases in LWin (Figure 6e). The large variation in SWin and LWin cloud effects between sites suggests 
https://doi.org/10.5194/tc-2022-24

Preprint. Discussion started: 17 February 2022

(c) Author(s) 2022. CC BY 4.0 License.

(c) (i)

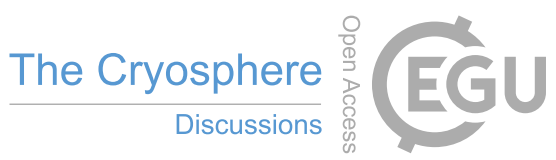

that different cloud types and cloud properties play a role in determining radiative forcing and this should be investigated in

future work. We note that changes in the profile of water vapour and air temperature (estimated by $e_{a}$ and $T_{a}$ ) also influence LWin (and to a much lesser extent SWin). Hence, the direct cloud effects shown here represent the combined effects of direct radiative forcing and changes to atmospheric profiles of water vapour and temperature, in contrast to analyses of cloud radiative forcing that consider the changes in incoming radiation with respect to calculated clear-sky values (e.g. Sicart et al., 2016).

(a) SWin

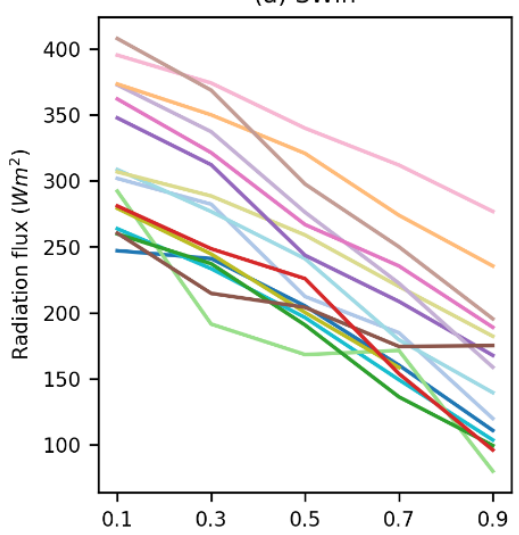

(d) SWin cloud effect

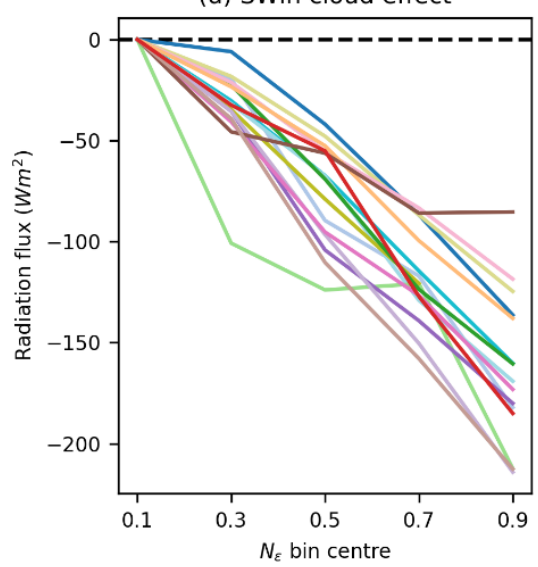

(b) LWin

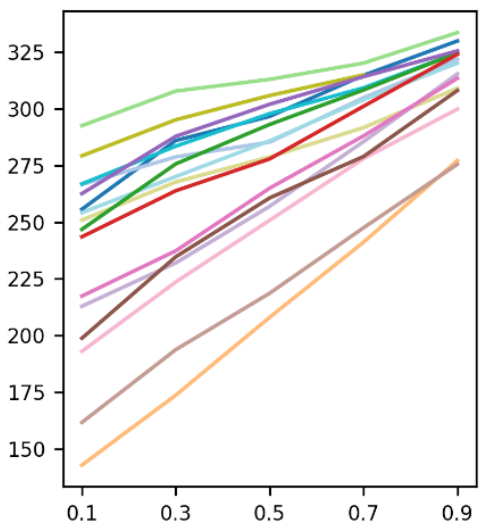

(e) LWin cloud effect

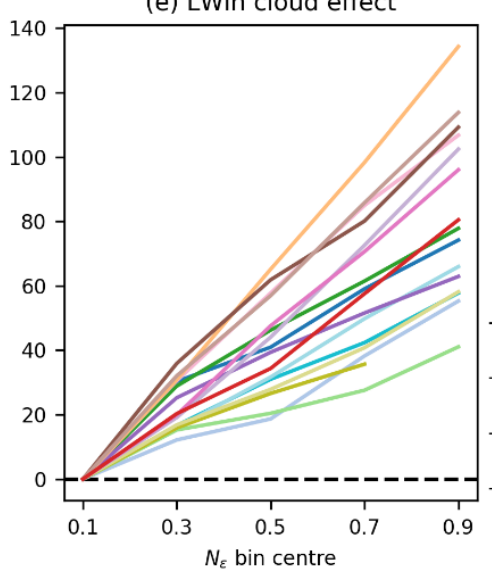

(c) SWin + LWin

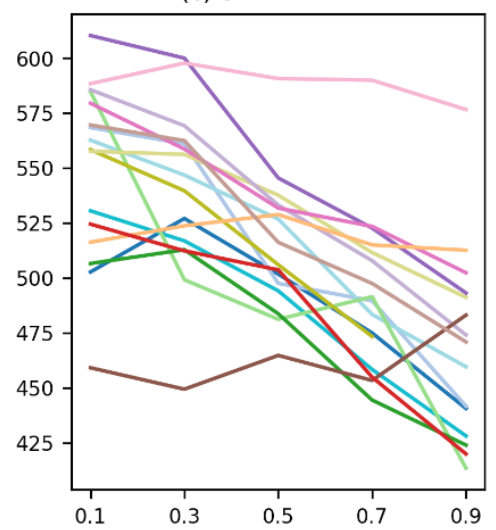

(f) SWin + LWin cloud effect

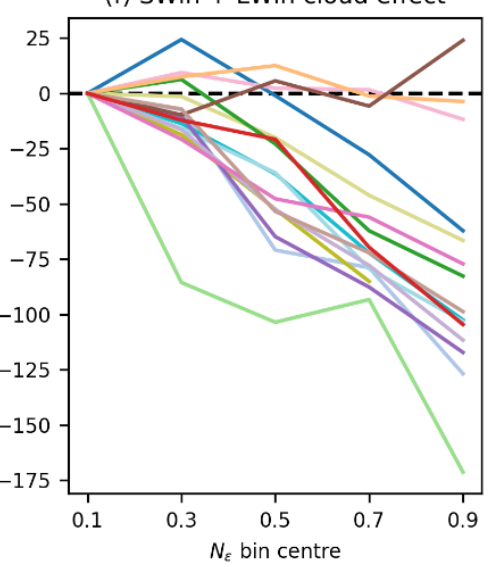

Figure 6: (a)-(c) Average melt season incoming radiation fluxes ( $\mathrm{SWin}, \mathrm{LWin}$ ) for different daily average cloud conditions $\left(N_{\varepsilon}\right)$, (d)(f) as for (a)-(c) expressed as change from clear-sky conditions $\left(N_{\varepsilon}<=0.2\right)$. Note y-axis range differs between panels.

By analysing the change in net radiation fluxes (SWnet, LWnet and Rnet) the effect of albedo and surface temperature is included with the direct effect of clouds on incoming radiation (Figure 7). A clear increase in Rnet during cloudy periods (positive Rnet cloud effect), aka 'radiation paradox', is observed at some sites: ZONG, MERA, LANG (Figure 7f), due to small negative SWnet effect and strong positive LWnet effect (Figure 7d,e). GUAN and KERS have a similarly strong positive LWnet effect at higher values of $N_{\varepsilon}$, but much more negative SWnet effects cancel these out. For most sites, the Rnet cloud 
https://doi.org/10.5194/tc-2022-24

Preprint. Discussion started: 17 February 2022

(c) Author(s) 2022. CC BY 4.0 License.

(c) (i)

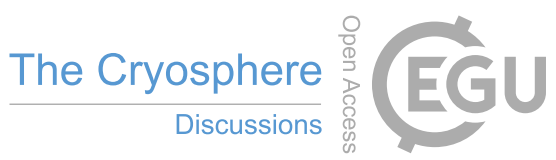

effect is small and negative ( 0 to $-20 \mathrm{~W} \mathrm{m-2}$ ). Many of these sites show a decrease in Rnet only at higher values of $N_{\varepsilon}$, while 3 sites show the highest Rnet in partial-cloud conditions, emphasising that the relationship between Rnet and cloudiness is not always linear. NORD, CABL, QASI, and CHHO all show a strong negative Rnet cloud effect, driven by strong negative SWnet effect and weak LWnet cloud effect. For the two sites with measurements from both the accumulation and the ablation areas, accumulation sites exhibit much more positive response to cloud compared with their ablation area counterparts, driven by the change in SWnet cloud effect (surface albedo) rather than large change in LWnet cloud effect.

(a) SWnet

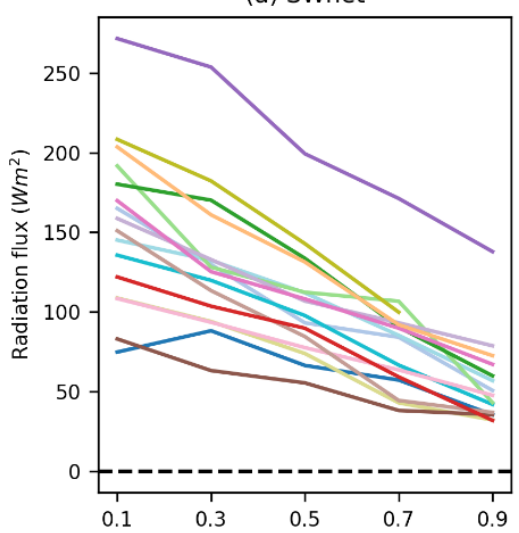

(d) SWnet cloud effect

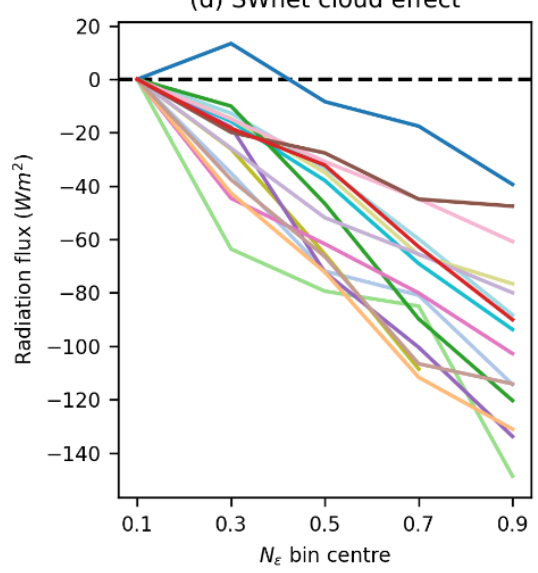

(b) LWnet

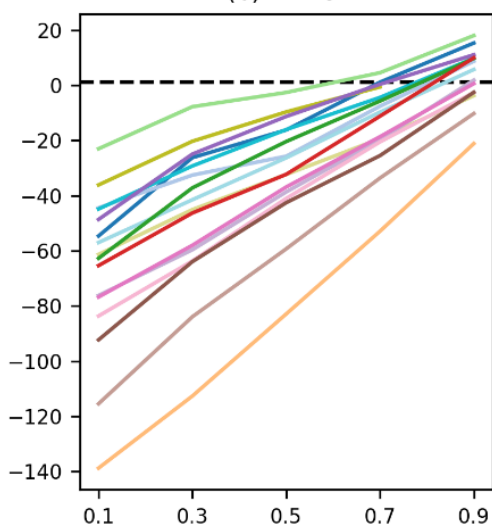

(e) LWnet cloud effect

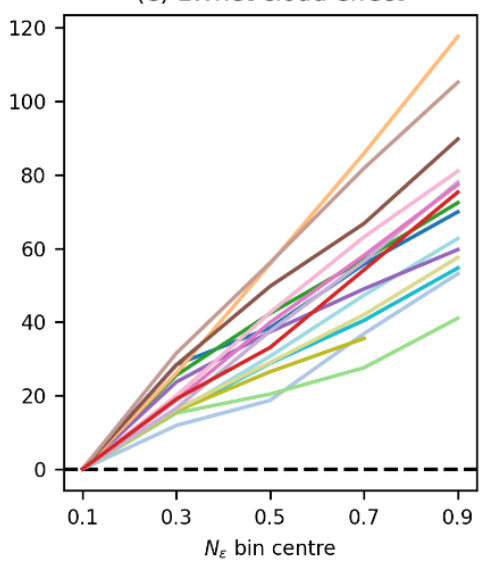

(c) Rnet

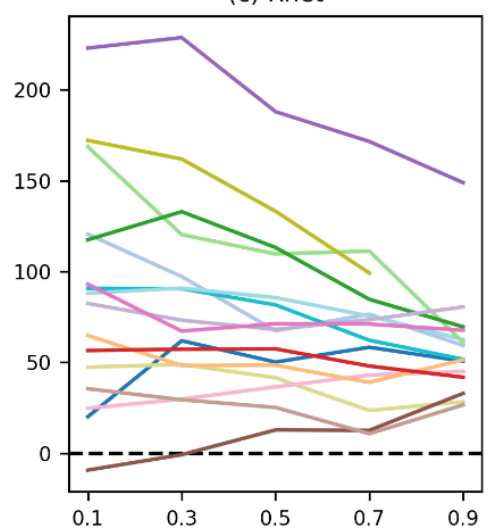

(f) Rnet cloud effect

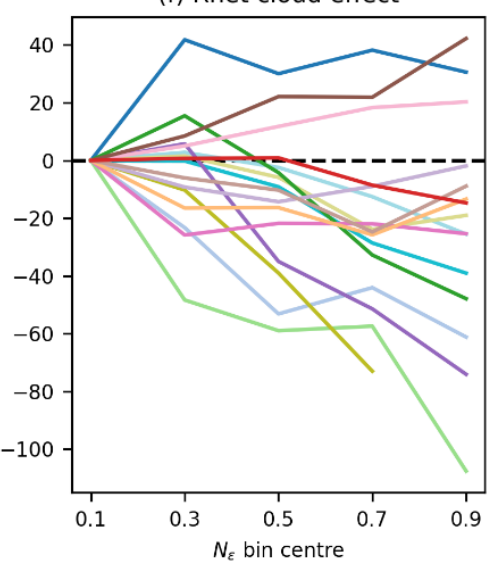

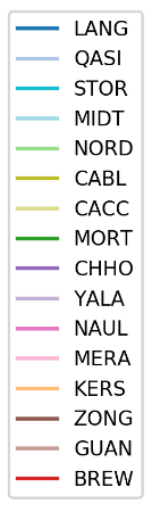

. 
average melt-season $T_{a} \gg 0^{\circ} \mathrm{C}$, increasing cloudiness is associated with lower temperatures, while at sites with average meltseason $T_{a}<0{ }^{\circ} \mathrm{C}$ (KERS, MERA, NAUL, YALA), cloud are generally associated with higher temperatures (Figure 8a). Average $T_{a}$ varies little with cloud cover at ZONG and CHHO. At most sites, wind speed decreases with increasing cloudiness (Figure 8b). The exceptions are BREW and STOR, which show moderate increases $\left(<1 \mathrm{~m} \mathrm{~s}^{-1}\right)$, LANG and MIDT, which show larger increases (1.6 and $2.9 \mathrm{~m} \mathrm{~s}^{-1}$, respectively), and QASI and CACC, where the relationship is weak and non-linear. We note that sites where wind speed increases with cloudiness (particularly MIDT and LANG) have a wind climate that is mainly influenced by the large-scale circulation, while other sites may have a more local wind climate where local or meso-scale katabatic or convective circulations prevail (e.g. Mölg et al., 2020; Conway et al., 2021). Stronger radiative cooling during clear-sky periods may promote higher katabatic wind speeds in clear-sky conditions, though the relationship is not simple; at ZONG, strong winds during clear-sky conditions are related to large-scale forcing during the dry season (Litt et al., 2014). As expected, $e_{a}$ and $R H$ increase with cloudiness, however some sites with $e_{a}$ around the saturation vapour pressure of melting surface show a weak relationship to cloudiness (e.g. QASI, CACC). The wide variation of $R H$ in clear-sky conditions ( $\sim 30$ to $\sim 70 \%$ ) implies that care should be taken when using $R H$ to model cloud cover using empirical parameterisations developed for particular study areas, or even at different altitudes (e.g. NAUL vs MERA).
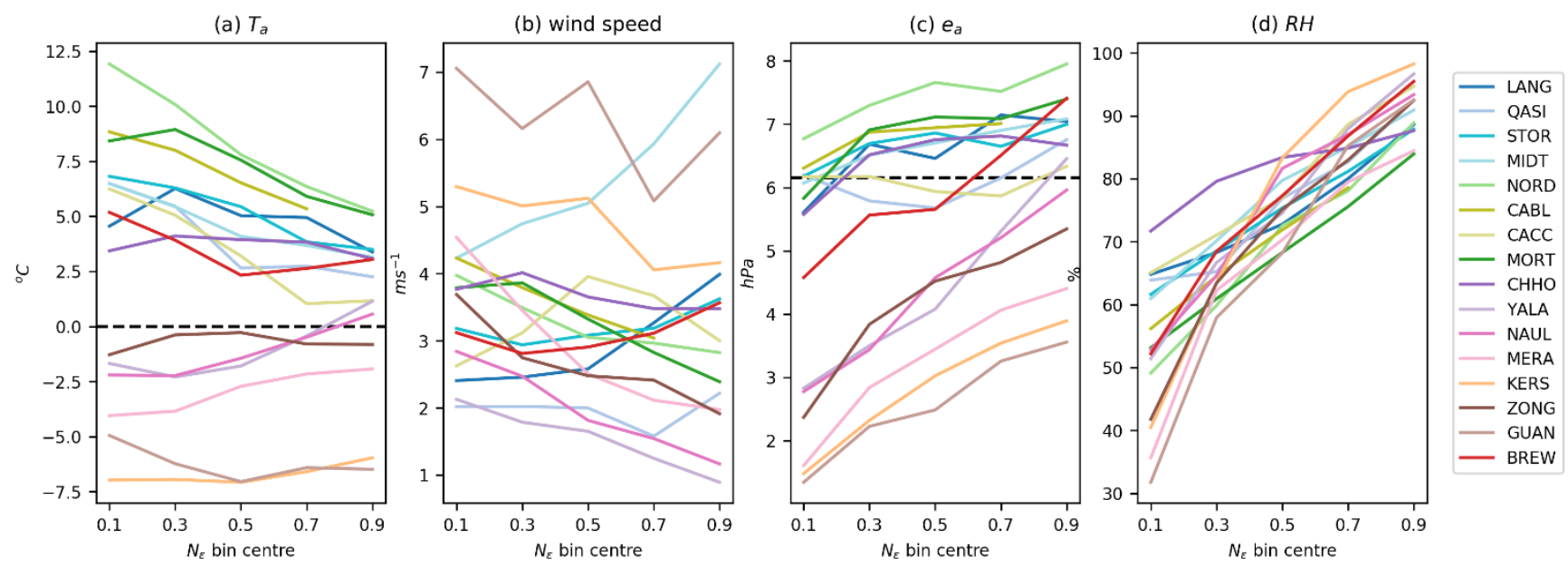

Figure 8: Average melt season near-surface meteorology for different daily average cloud conditions $\left(N_{\varepsilon}\right)$. Dashed lines indicate melting point temperature in (a) and saturation vapour pressure in (c).

\subsection{Variation of melt frequency, melt amount and SEB with cloudiness}

The percentage of hours with surface melt increases with cloudiness at all study sites (Figure 9). Colder sites across the Himalaya and tropical regions (except KERS) show the largest increases with respect to clear-sky conditions (up to 5 times more frequent), while BREW, MORT and LANG all show moderate increases up to 1.5 times more frequent in overcast 
conditions. Other European and North American sites show comparatively high melt frequency across all cloud conditions, indicative of the warm conditions where $e_{a}$ exceeds that of a melting ice/snow surface. Even in these conditions, periods with surface melt still become more common with increasing cloudiness, with $100 \%$ of overcast periods at NORD experiencing melt (Figure 9a). While analysis of diurnal patterns of melt is beyond the scope of this paper, it is likely that night time cooling during clear-sky conditions delays the onset of melt in the morning, whereas in cloudy conditions the surface can remain close to melting conditions day and night. MERA shows the largest increase in melt frequency with cloudiness, with melt 5 times more frequent in overcast (26\% of overcast conditions) compared to clear-sky conditions (5\%). A consistent increase with cloudiness is observed at MERA but caution is warranted given the small number of hours with melt in clear-sky conditions (20 hours).
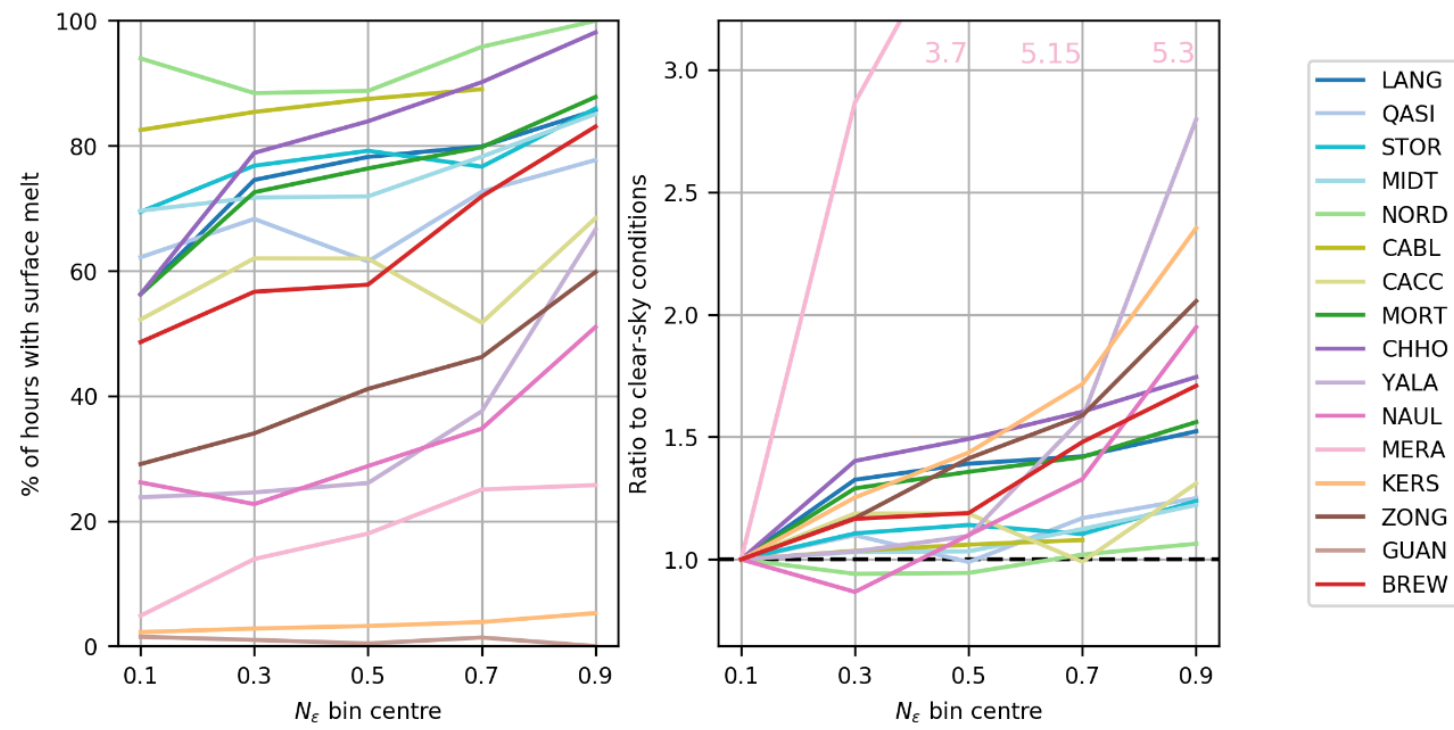

Figure 9: (a) Percentage of hours with surface melt for different cloud conditions $\left(N_{\varepsilon}\right)$ during melt season, (b) as for (a) shown as fraction with respect to clear-sky conditions $\left(N_{\varepsilon}<=0.2\right)$. Note GUAN is excluded from panel (b) due to insufficient datapoints and for clarity some points for MERA are shown as text within the panel.

In contrast to the fraction of time with surface melt, the relationship between the amount of energy available for melt $\left(Q_{M}\right)$ and cloudiness does not show a universal variation, with sites showing increased, decreased or no change with increasing cloudiness on average (Figure 10). Around half the sites show a general reduction of daily average $Q_{M}$ with increasing cloudiness, particularly those in North America (CABL, CACC, NORD) and some European sites (MIDT, MORT, STOR) along with QASI and CHHO. LANG, MERA and KERS show large relative increase in $Q_{M}$ with cloudiness, while BREW, ZONG and YALA show a more mixed response with a small increase in melt in overcast conditions. LANG and NAUL display a sharp change from clear-sky conditions to the first partial cloud bin $\left(N_{\varepsilon} \sim 0.3\right)$, but little change with increasing cloudiness. 
https://doi.org/10.5194/tc-2022-24

Preprint. Discussion started: 17 February 2022

(c) Author(s) 2022. CC BY 4.0 License.

(c) (i)
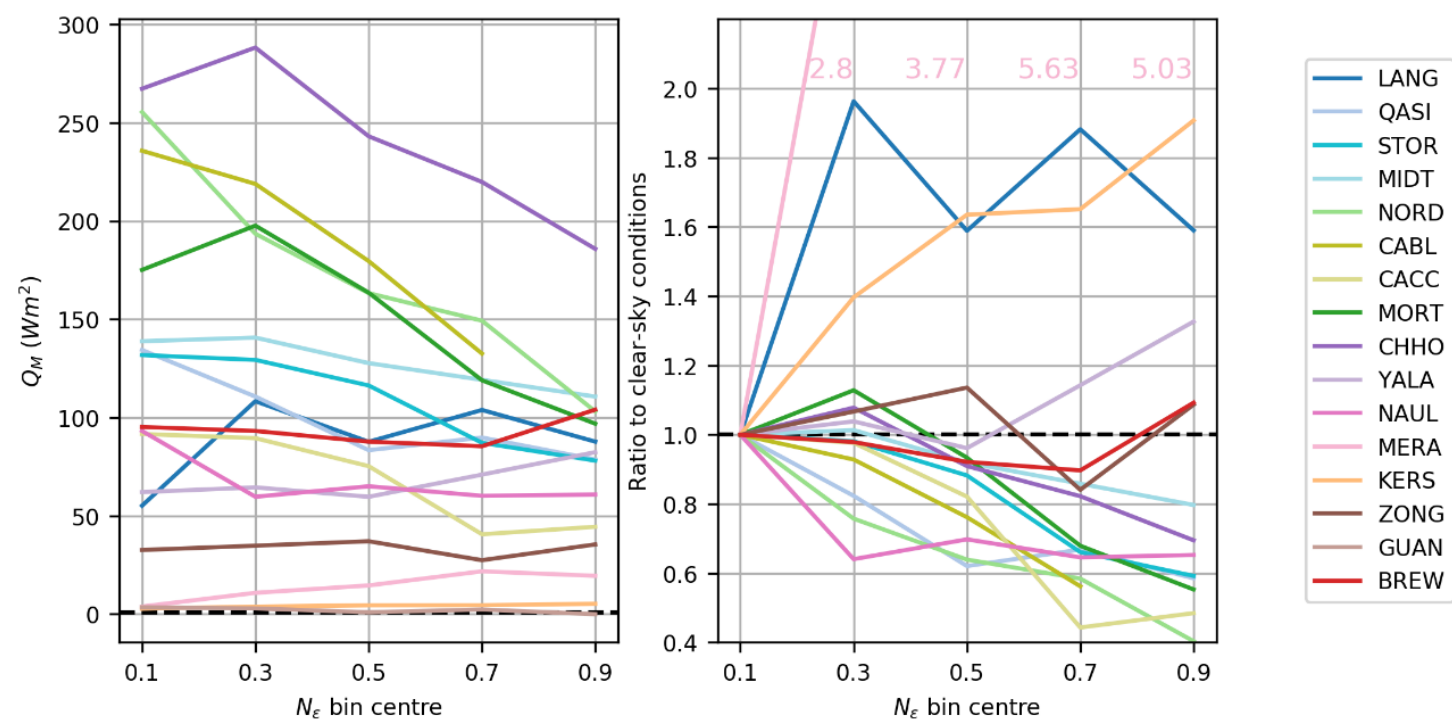

Figure 10: (a) Average melt season $Q_{M}$ for different cloud conditions $\left(N_{\varepsilon}\right)$ (b) as for (a) shown as fraction with respect to clear-sky conditions $\left(N_{\varepsilon}<=0.2\right)$. Note GUAN is excluded from panel (b) due to insufficient datapoints and for clarity some points for MERA are shown as text within the panel.

As cloudiness increases, the source of $Q_{M}$ changes; at all sites, the contribution of $S W n e t$ reduces and a greater proportion of $Q_{M}$ comes from the temperature-dependent fluxes (LWnet, $Q_{S}$ and $Q_{L}$ ) (Figure 11a,f; see Figure A5 for absolute values). At colder and drier sites (KERS, MERA, GUAN, NAUL, YALA, ZONG), negative $Q_{L}$ reduces $Q_{M}$ during clear-sky periods, but this effect reduces towards 0 as cloudiness increases. At the coldest sites (KERS, MERA and ZONG), $Q_{L}$ remains negative during melt (indicating evaporation) even in overcast conditions. Small $Q_{S}$ fluxes at MERA, NAUL, YALA, ZONG are due to $T_{a}$ values during melt remaining around $0{ }^{\circ} \mathrm{C}$. At other sites, the proportion of melt from $Q_{S}$ remains fairly static with cloudiness, despite decreasing in absolute magnitude (Figure A5) due to decreases in $T_{a}$ (Figure 8a). The exceptions are BREW, MIDT, and QASI where the contribution from $Q_{S}$ increases with cloudiness and ZONG where the contribution of $Q_{S}$ decreases. Note that as Figure 11 presents averages for only periods with surface melt, LWout is constant and changes in LWnet are entirely due to LWin. 
https://doi.org/10.5194/tc-2022-24

Preprint. Discussion started: 17 February 2022

(c) Author(s) 2022. CC BY 4.0 License.

(c) (i)

(a) SWnet

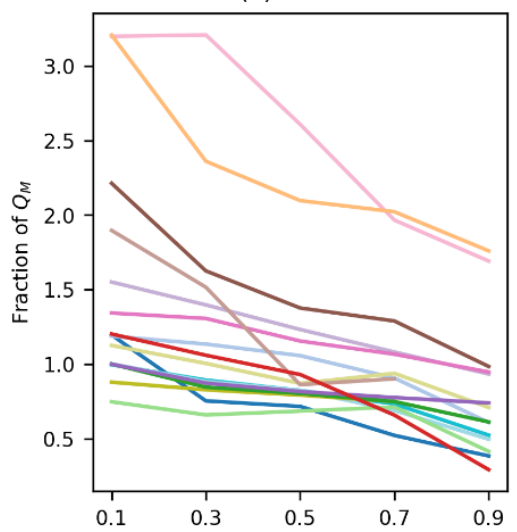

(d) $Q_{S}$

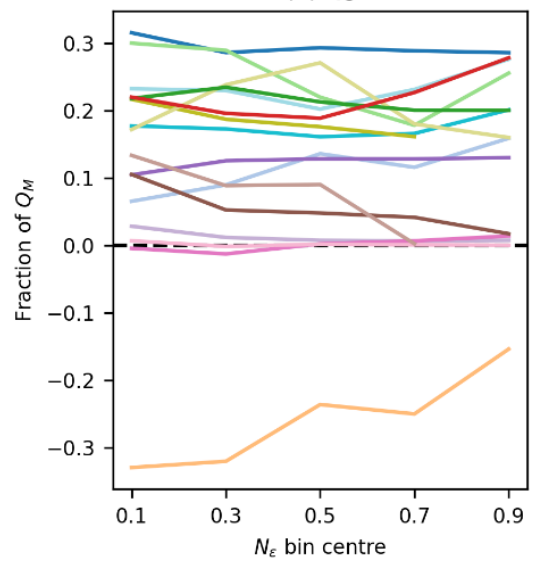

(b) LWnet

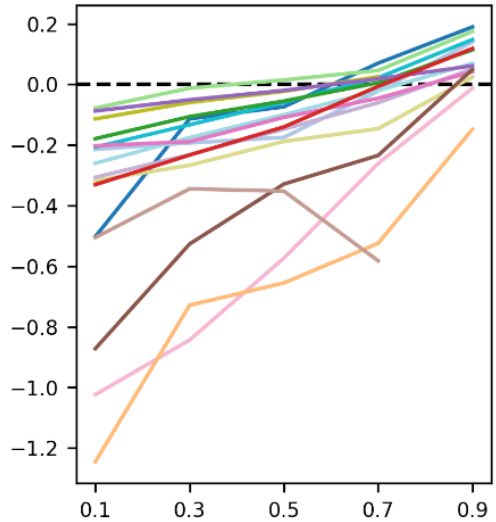

(e) $Q_{L}$

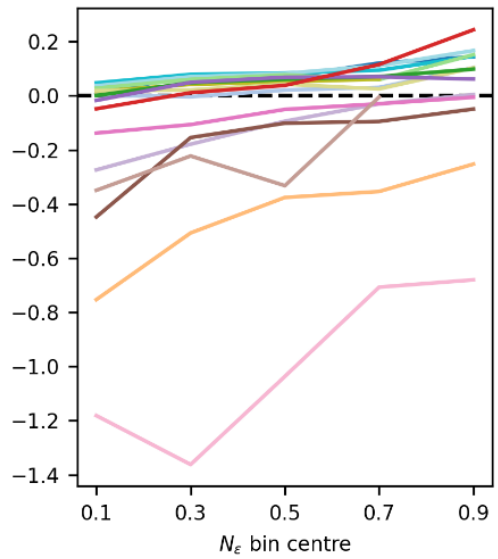

(c) Rnet

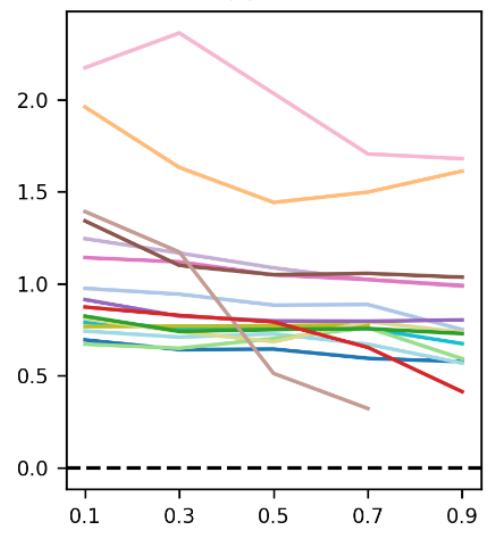

(f) $L W n e t+Q_{S}+Q_{L}$

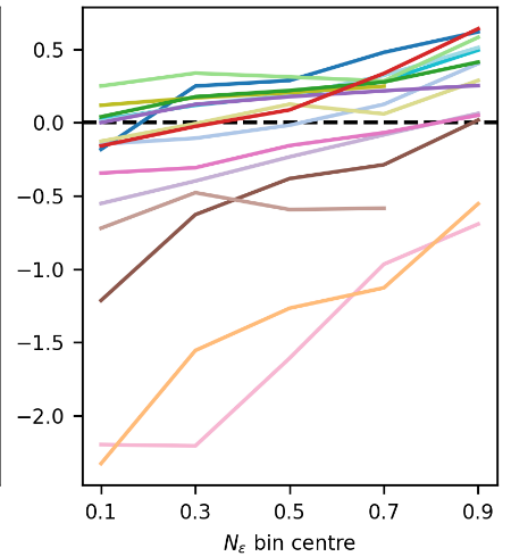

Figure 11: Average melt season SEB terms during hours with surface melt for different cloud conditions $\left(N_{\varepsilon}\right)$. Variables are shown as a fraction of average $Q_{M}$ during hours with surface melt in each respective cloud condition $\left(N_{\varepsilon}\right)$. Note y-axis range differs between panels.

\section{Discussion}

\subsection{Regional and elevational patterns}

Two groups of sites with a broadly similar response emerge from the above analyses, largely split by latitude, but also air temperature and continentality. The first group (YALA, NAUL, MERA, KERS, ZONG) consists of high-altitude sites in the Himalaya (excluding CHHO) and tropical regions. These sites are comparatively cold, with negative $Q_{L}$ and small $Q_{S}$ during melt. During cloudy conditions, these sites experience warmer and calmer conditions, reduced evaporation/sublimation (less negative or, at times, positive $Q_{L}$ ) and a large increase in the fraction of time that melt occurs, regardless of the seasonality of cloud or the typical cloud conditions (e.g. KERS vs MERA). These sites also generally experience greater $Q_{M}$ in cloudy periods (except for NAUL) when averaged over a long melt season that includes months with marginal melt conditions. Some sites 
experience a radiation paradox where Rnet increases with cloudiness, while others show a small decrease in Rnet with cloudiness. While GUAN experiences similar patterns of near-surface meteorology and radiation as the sites in this group, it experiences very infrequent melt.

The second group consists of the mid-latitude sites outside the Himalaya (LANG, QASI, STOR, MIDT, NORD, CABL, CACC, MORT, BREW) as well as CHHO. These sites experience higher average melt season $T_{a}$, and $T_{a}$ generally decreases with cloudiness. Despite decreased $T_{a}$, melt becomes more frequency in cloudy conditions. With a few exceptions (e.g. BREW, LANG), $Q_{M}$ decreases with increased cloudiness, though the magnitude of decrease varies widely (from $20 \%$ to $60 \%$ less in overcast compared to clear-sky conditions). CHHO stands out from the other Himalayan sites in that it has a higher average $T_{a}$ that does not vary greatly with cloudiness. Here also, low albedo drives a strong negative Rnet cloud effect that, in turn, drives a large decrease in $Q_{M}$ during cloudy periods. At all sites, $Q_{S}$ is positive in all cloud conditions, though the absolute magnitude is generally reduced in cloudy periods due to decreased $T_{a}$. Cloud is associated with increased wind speed at most maritime sites (LANG, MIDT, STOR, BREW) but does not show a consistent relationship to $Q_{M}$; MIDT and STOR experience less $Q_{M}$ in cloud conditions, whereas LANG and BREW experience greater $Q_{M}$ due to increased wind speed and comparatively modest decreases in $T_{a}$ that drive increased $L W n e t$ and $Q_{L}$. In the case of LANG, increased $Q_{M}$ during cloud is also due to a positive Rnet cloud effect.

Locations with AWS at two elevations highlight more positive Rnet cloud effects at accumulation sites than ablation sites due to the higher albedo and larger difference between clear-sky and overcast emissivity. Differences in melt are stronger at the Himalayan pair, where melt is decreased in cloudy conditions at the lower sites and increased during cloud at the upper site. At the pair in Canada, both sites experience reduced melt during cloudy conditions, though in absolute terms, the decrease is larger in the ablation area.

\subsection{Melt cloud effect}

While the average change in $Q_{M}$ with cloudiness is small at some sites, it is instructive to assess whether the average $Q_{M}$ cloud effect (CE) at the various sites can be related to geographic or climatic parameters. Figure 12a,b shows the average relationship between cloudiness and melt at the various sites does not follow easy relationships with latitude or altitude. Neither average near-surface air temperature or humidity shows a clear relationship with the $Q_{M} \mathrm{CE}$, though colder sites generally have smaller $Q_{M}$ CE than warmer sites (Figure 12c, d). Changes in SWin CE alone do not show a clear explanation, though when combined with influence of $L$ Win CE, a clearer pattern emerges (Figure 12f). Surface albedo shows a clear though weak correlation to $Q_{M} \mathrm{CE}$, while the Rnet $\mathrm{CE}$ shows the clearest relationship to $Q_{M} \mathrm{CE}$ (Figure 12g). In general, sites that experience a radiation paradox (LANG, ZONG, MERA) also experience greater melt in cloudy conditions (positive $Q_{M} \mathrm{CE}$ ), while sites with negative Rnet CE experience less melt in cloudy conditions (Figure 12g). 
(c)

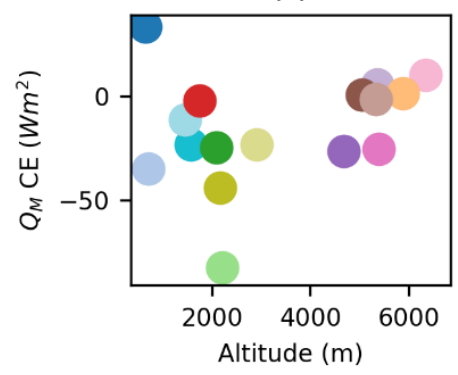

(e)

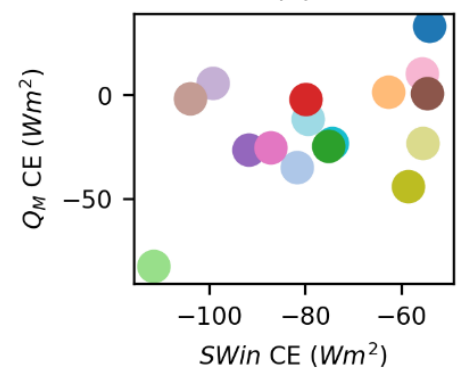

(b)

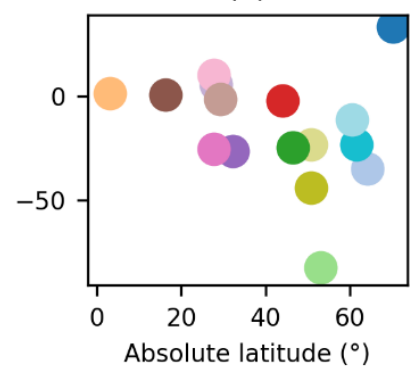

(f)

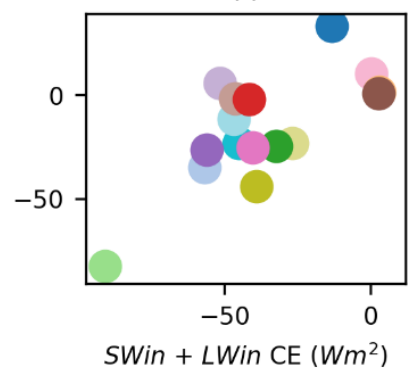

(c)

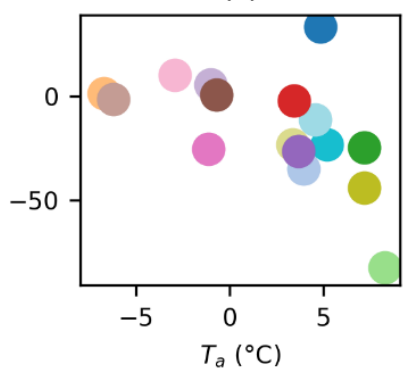

(g)

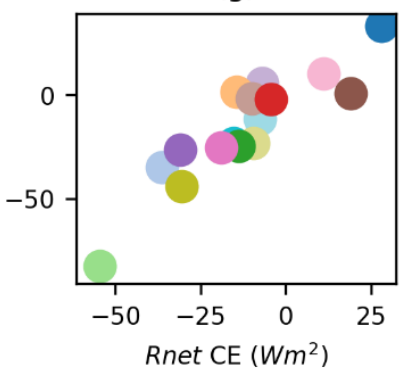

(d)

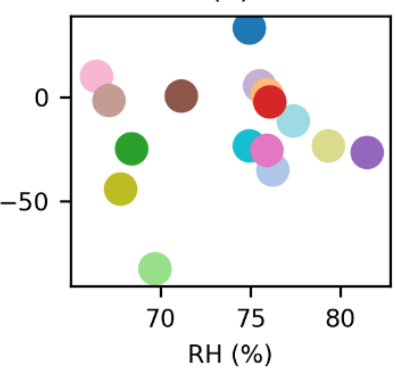

(h)

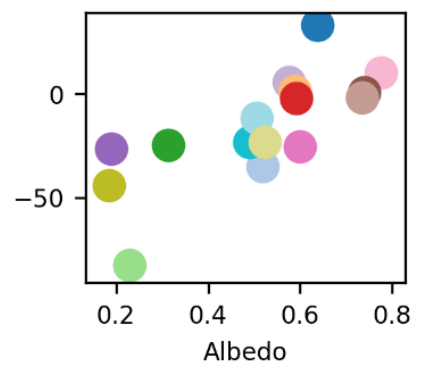

Figure 12: The variation of average melt season $Q_{M}$ cloud effect (CE) with (a) station altitude, (b) absolute station latitude, (c) average melt-season $T_{a}$, (d) average melt season $R H$, (e) SWin CE, (f) SWin+LWin CE, (g) Rnet CE and (h) albedo. See Section 2.5 for definition of CE. Colours denote sites - see legend on Figure 11.

\subsection{Limitations}

While efforts have been made to homogenise the datasets, it is possible that biases still affect the results. Interannual variability causes uncertainty, particularly for sites with only one or two seasons (e.g. NORD, ZONG). Giesen et al. (2008 Table 4) show that at MIDT, the contribution of SEB components to melt during clear-sky periods can vary up to $12 \%$ between years, while variability in overcast periods is less. The interannual variability is partly influenced by the seasonality of anomalies in cloudiness, with strong anomalies in spring causing the importance of $Q_{S}$ to melt to change markedly. Some sites also have discontinuous records (CABL, CACC, NORD, CHHO) that do not include periods with lower melt rate outside the peak melt season. Increased clear-sky solar radiation and $T_{a}$ as well as decreased albedo during the peak melt season are likely to cause Rnet and $Q_{M}$ cloud effects to be larger at these sites compared to those with longer records that include periods of more marginal melt. This effect is demonstrated by repeating the analysis but restricting the melt season to months with at least $80 \%$ of the maximum monthly-average $Q_{M}, 2-3$ months at each site (Figure A6). Figure 13 shows the relationship between average $Q_{M}$ and $N_{\varepsilon}$ for the period with peak melt rates at each site. The previously large increase in $Q_{M}$ with cloud at MERA and LANG becomes more variable, and $Q_{M}$ is smaller in overcast conditions compared to clear-sky. This is primarily due to the removal of months with a high albedo snow surface in the early season where a strong radiation paradox drives an increase in melt during cloud periods. In clear-sky conditions, higher $T_{a}$ and $e_{a}$ in the peak melt season creates generally positive $Q_{L}$ at these 
https://doi.org/10.5194/tc-2022-24

Preprint. Discussion started: 17 February 2022

(c) Author(s) 2022. CC BY 4.0 License.

(c) (i)

sites (not shown). BREW also now shows a moderate decrease in $Q_{M}$ with cloud, while ZONG shows a much stronger decrease due to marked seasonal changes in the SEB terms driving melt (less negative LWnet and $Q_{L}$ in austral spring and summer; Figure A2). Only one site (YALA) still shows its highest $Q_{M}$ in overcast conditions, but the increase is small compared to the average for the longer melt season. In fact, at outer-tropical sites such as ZONG where melt can occur in most months alongside large seasonal variations in climate, the analysis here likely mixes cloud effects with seasonal changes of other meteorological forcings (such as potential solar irradiance and air temperature).

Seasonal changes in cloud effects on melt have been previously reported by some studies; Giesen et al. (2008) show that negative $Q_{M}$ cloud effects at MIDT were restricted to July and August, with other months showing neutral or positive cloud effects; Conway and Cullen (2016) show only one month with negative $Q_{M}$ cloud effect at BREW, with positive effects in other months; Chen et al. (2021) report strong negative $Q_{M}$ cloud effects in July and August, with weaker negative effects in May and June, and neutral effects in September. The fact that average results are sensitive to the definition of the melt season highlights the complex physical relationships between cloudiness, near-surface meteorology and melt. While future work could analyse seasonal changes in cloud effect in more detail, caution is warranted in efforts to simplify or generalise these relationships. The analysis does highlight the need to capture AWS records through the full annual cycle at study sites in order to fully understand the relationships between meteorological forcing and melt. Future work should also assess the mechanisms driving the observed covariance between cloudiness and near-surface meteorology, e.g. Do large-scale changes in airmass or local/meso-scale processes drive changes in $T_{a}$ with cloud? How well are these processes represented in the datasets used to force glacier melt models on regional scales? 

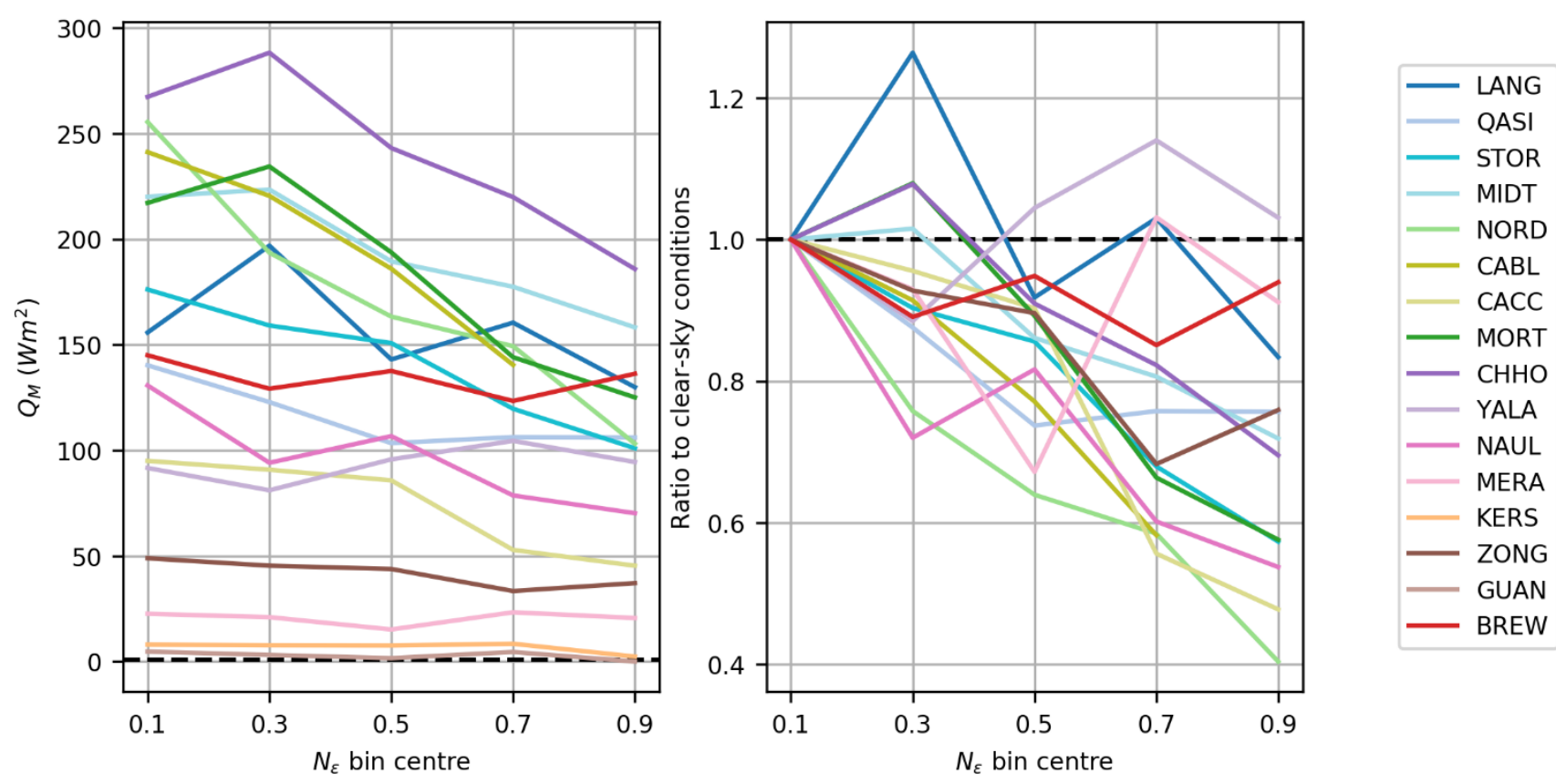

Figure 13: As for Figure 10 but only for months with $>80 \%$ of maximum monthly-average $Q_{M}$. Note GUAN and KERS are excluded from panel (b) due to insufficient datapoints.

The derivation of cloudiness from $L$ Win also poses challenges. At some sites (e.g. LANG, and MORT), $\varepsilon_{c s}$ shows a poor fit at higher vapour pressure, with incoming LWin during clear-sky periods being higher than that expected from the theoretical curves (Figure 4). This mismatch between theoretical and observed $\varepsilon_{c s}$ during periods of higher $e_{a}$ may cause some clear-sky periods to be misclassified as being in first partial cloud bin $\left(N_{\varepsilon} \sim 0.3\right)$. Indeed, at both LANG and MORT, the $N_{\varepsilon} \sim 0.3$ bin shows higher melt, indicating this may be the case. The reasons for this mismatch have not been investigated, but it may be due to a different method use to correct LWin data (Giesen et al, 2014) or changes in water vapour profiles in the atmospheric boundary layer.

\subsection{Implications for glacier melt modelling}

Previous research that identified a higher sensitivity to warming associated with cloud at BREW (Conway and Cullen, 2016),

showed this occurred without increased melt during cloud periods. The effect was primarily due to increased melt frequency and temperature-dependent fluxes during cloudy periods as well as accumulation-albedo feedbacks. All sites analysed here show increased melt frequency and temperature-dependent fluxes during cloudy periods, suggesting more sites may also experience a higher sensitivity to warming associated with cloud. While a formal analysis is beyond the scope of this paper, we may therefore expect that the response of melt to past and future temperature change will be modified by changes to 
atmospheric moisture in the form of clouds and vapour fluxes. The simplified models that are generally used to predict future glacier change do not account for these effects. If they do include the effects of clouds, they generally only include the opposite effect - a reduction in solar radiation by clouds - and therefore may underestimate future melt at sites where cloud cover is not universally associated with reduced melt (e.g. high altitude and maritime glacier sites). Furthermore, any increase in clouds and atmospheric moisture accompanying future warming may result in greater melting than predicted. Given the positive effect of clouds on net radiation at snow covered and high-altitude sites, future increases in cloud cover may promote further melt, especially during marginal melt seasons. However, caution is warranted in making generalisations as the analysis here shows that even in this set of 16 glaciers, we find variability in the links between clouds and melt, and it seems that some processes are site specific even in this small sample.

480 The non-linear relationships between clouds and melt motivates the use of SEB models in regional and global assessments of glacier response to climate change. To aid in the development of globally and regionally applicable SEB models and parameter sets, the research community should investigate creating a central open-source repository for glacier AWS and SEB datasets along with supporting meta data. Such a repository would facilitate the easy transfer of data between researchers, streamline processing by establishing data format and meta data standards, as well as motivating best-practice in data collection and quality control. Alongside this, careful assessments of SWin and LWin and their relationship to near-surface meteorology from global, regional and meso-scale meteorological models should be undertaken to ensure uncertainties in model input data are reduced and to assess the need for downscaling to account for local-scale processes. As many models rely on empirical relationships between SWin and LWin to account for local-scale changes in topography, globally applicable parameterisations of SWin and LWin should be tested.

\section{Conclusions}

Sixteen high-quality published datasets of near-surface meteorology, radiation, and surface energy balance from very different climate settings have been homogenised and analysed in a common framework. The analyses sought to assess how the relationships between clouds, near-surface meteorology and surface energy balance vary in different mountain glacier environments. Distinct regional differences in the seasonality of cloudiness are demonstrated between different mountain glacier environments. On average, over the main period of melt at each site:

- Near-surface humidity is shown to universally increase in cloudy conditions, whereas a divergent relationship is found between near-surface air temperature and cloudiness; at colder sites (average near-surface air temperature in melt season $<0{ }^{\circ} \mathrm{C}$ ), air temperature is increased in cloudy conditions, while for warmer sites (average near-surface air temperature in melt season $\gg 0^{\circ} \mathrm{C}$ ), air temperature decreases in cloudy conditions. Wind speed shows a mixed association to cloudiness at different sites. 
- Most sites show, on average, a modest to strong decrease in net radiation during cloudy conditions during the melt season. A few sites show a clear increase in net radiation with cloud - aka 'radiation paradox' - but this result is sensitive to the months used in the analysis due to seasonal changes in incoming radiation fluxes and albedo.

- At all sites, surface melt is more frequent in cloudy conditions compared to clear skies.

- At all sites, temperature-dependent fluxes contribute a larger fraction of melt energy during cloudy conditions, primarily due to increases in incoming longwave radiation and turbulent latent heat fluxes. The contribution of turbulent sensible heat generally varies little with cloudiness.

- Cloud cover does not affect daily total melt in a universal way, with some sites showing increased melt energy in cloudy conditions and other decreased melt energy. The association of clouds with melt energy is complex and not amenable to simple relationships due to many interacting physical processes (varies with latitude, average melt-season air temperature, degree of continentality, season, and elevation). However, the association of clouds and melt is most closely related to net radiation cloud effect, with sites displaying a radiation paradox also showing an increase in energy for melt in cloudy conditions.

515 The non-linear relationships between clouds, near-surface meteorology and melt motivate the use of physics-based surface energy balance models for understanding future glacier response to climate change, particularly in areas where atmospheric moisture plays a key role both in accumulation and ablation processes (e.g. Himalaya, tropical glaciers, maritime glaciers). Future work should also look to carefully assess shortwave and longwave radiation fluxes and their relationships with nearsurface meteorology in global, regional and meso-scale meteorological model analyses if we are to confidently use these tools to better understand how future glacier melt will respond to changes in atmospheric temperature.

\section{Data availability}

AWS data is available from individual paper authors listed in Table 1.

\section{Author contributions}

JC conceptualized the study, curated the data, conducted the formal analyses, and wrote the manuscript. Other co-authors supplied data suitable for curation, aided in the investigation and reviewed/edited the manuscript.

\section{Acknowledgements}

JCs contribution to this research was supported by the Royal Society of New Zealand Marsden Fund. The authors wish to 530 thank the following additional people and organisations for data contributions and funding data collection and processing: Maxime Litt, Hans Oerlemans, GLACIOCLIM, PROMICE, the Greenland Ecosystem Monitoring Programme, ICIMOD, 
https://doi.org/10.5194/tc-2022-24

Preprint. Discussion started: 17 February 2022

(c) Author(s) 2022. CC BY 4.0 License.

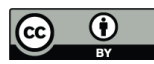

Antoine Rabatel (IGE), Alvaro Soruco (UMSA, Bolivia), LMI GREATICE, NSERC Discovery Grant and Research Tools and Instruments, Canada Foundation for Innovation. MFA acknowledges research grants from IFCPAR and IRD, France.

\section{References}

535 Abermann, J., Van As, D., Wacker, S., Langley, K., Machguth, H., and Fausto, R. S.: Strong contrast in mass and energy balance between a coastal mountain glacier and the Greenland ice sheet, Journal of Glaciology, 65, 263-269, 10.1017/jog.2019.4, 2019.

Ambach, W.: The influence of cloudiness on the net radiation balance of a snow surface with high albedo, Journal of Glaciology, 13, 73-84, 10.3189/S0022143000023388, 1974.

540 Andreassen, L. M., Van Den Broeke, M. R., Giesen, R. H., and Oerlemans, J.: A 5 year record of surface energy and mass balance from the ablation zone of Storbreen, Norway, Journal of Glaciology, 54, 245-258, 10.3189/002214308784886199, 2008.

Azam, M. F., Wagnon, P., Vincent, C., Ramanathan, A. L., Favier, V., Mandal, A., and Pottakkal, J. G.: Processes governing the mass balance of Chhota Shigri Glacier (western Himalaya, India) assessed by point-scale surface energy balance measurements, The Cryosphere, 8, 2195-2217, 10.5194/tc-8-2195-2014, 2014.

Brutsaert, W.: A Theory for Local Evaporation (or Heat Transfer) From Rough and Smooth Surfaces at Ground, Water Resources Research, 11, 543-550, 10.1029/WR011i004p00543, 1975.

Buck, A. L. A. L.: New Equations for Computing Vapor Pressure and Enhancement Factor, Journal of Applied Meteorology, 20, 1527-1532, 10.1175/1520-0450(1981)020<1527:NEFCVP>2.0.CO;2, 1981.

550 Chen, J., Du, W., Kang, S., Qin, X., Sun, W., Liu, Y., Jin, Z., Li, Y., and Wang, L.: Eight-year analysis of radiative properties of clouds and its impact on melting on the Laohugou Glacier No. 12, western Qilian Mountains, Atmospheric Research, 250, 10.1016/j.atmosres.2020.105410, 2021.

Church, J. A., White, N. J., Konikow, L. F., Domingues, C. M., Cogley, J. G., Rignot, E., Gregory, J. M., van den Broeke, M. R., Monaghan, A. J., and Velicogna, I.: Revisiting the Earth's sea-level and energy budgets from 1961 to 2008, Geophysical Research Letters, 38, L18601, 10.1029/2011g1048794, 2011.

Conway, J. P. and Cullen, N. J.: Cloud effects on surface energy and mass balance in the ablation area of Brewster Glacier, New Zealand, The Cryosphere, 10, 313-328, 10.5194/tc-10-313-2016, 2016.

Conway, J. P., Cullen, N. J., Spronken-Smith, R. A., and Fitzsimons, S. J.: All-sky radiation over a glacier surface in the Southern Alps of New Zealand: characterizing cloud effects on incoming shortwave, longwave and net radiation, International Journal of Climatology, 35, 699-713, 10.1002/joc.4014, 2015.

Conway, J. P., Helgason, W. D., Pomeroy, J. W., and Sicart, J. E.: Icefield breezes: mesoscale diurnal circulation in the atmospheric boundary layer over an outlet of the Columbia Icefield, Canadian Rockies, Journal of Geophysical Research: Atmospheres, 126, e2020JD034225, 10.1029/2020jd034225, 2021.

Cullen, N. J. and Conway, J. P.: A 22 month record of surface meteorology and energy balance from the ablation zone of Brewster Glacier, New Zealand, Journal of Glaciology, 61, 931-946, 10.3189/2015JoG15J004, 2015.

Cullen, N. J., Anderson, B., Sirguey, P., Stumm, D., Mackintosh, A., Conway, J. P., Horgan, H. J., Dadic, R., Fitzsimons, S. J., and Lorrey, A.: An 11-year record of mass balance of Brewster Glacier, New Zealand, determined using a geostatistical approach, Journal of Glaciology, 1-19, 10.1017/jog.2016.128, 2016.

Fitzpatrick, N., Radić, V., and Menounos, B.: Surface Energy Balance Closure and Turbulent Flux Parameterization on a Mid- 
https://doi.org/10.5194/tc-2022-24

Preprint. Discussion started: 17 February 2022

(c) Author(s) 2022. CC BY 4.0 License.

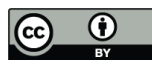

Fitzpatrick, N., Radić, V., and Menounos, B.: A multi-season investigation of glacier surface roughness lengths through in situ and remote observation, The Cryosphere, 13, 1051-1071, 10.5194/tc-13-1051-2019, 2019.

Giesen, R. H., Andreassen, L. M., Oerlemans, J., and Van Den Broeke, M. R.: Surface energy balance in the ablation zone of Langfjordjøkelen, an arctic, maritime glacier in northern Norway, Journal of Glaciology, 60, 57-70, 10.3189/2014JoG13J063, 2014.

Giesen, R. H., Andreassen, L. M., van den Broeke, M. R., and Oerlemans, J.: Comparison of the meteorology and surface energy balance at Storbreen and Midtdalsbreen, two glaciers in southern Norway, The Cryosphere, 3, 57-74, 10.5194/tc-3-572009, 2009.

Giesen, R. H., van den Broeke, M. R., Oerlemans, J., and Andreassen, L. M.: Surface energy balance in the ablation zone of

Midtdalsbreen, a glacier in southern Norway: Interannual variability and the effect of clouds, Journal of Geophysical Research, 113, 10.1029/2008jd010390, 2008.

Greuell, W., Knap, W. H., and Smeets, C. J. P. P.: Elevational changes in meteorological variables along a midlatitude glacier during summer, Journal of Geophysical Research, 102, 25941-25954, 1997.

Hock, R.: Temperature index melt modelling in mountain areas, Journal of Hydrology, 282, 104-115, 10.1016/s00221694(03)00257-9, 2003.

Hock, R., de Woul, M., Radić, V., and Dyurgerov, M.: Mountain glaciers and ice caps around Antarctica make a large sealevel rise contribution, Geophysical Research Letters, 36, L07501, 10.1029/2008g1037020, 2009.

Hugonnet, R., McNabb, R., Berthier, E., Menounos, B., Nuth, C., Girod, L., Farinotti, D., Huss, M., Dussaillant, I., Brun, F., and Kaab, A.: Accelerated global glacier mass loss in the early twenty-first century, Nature, 592, 726-731, 10.1038/s41586590 021-03436-z, 2021.

Huss, M. and Hock, R.: Global-scale hydrological response to future glacier mass loss, Nature Climate Change, 8, 135-140, 10.1038/s41558-017-0049-x, 2018.

Huybrechts, P. and Oerlemans, J.: Response of the Antarctic ice sheet to future greenhouse warming, Climate Dynamics, 5, 93-102, 10.1007/BF00207424, 1990.

595 Kraaijenbrink, P. D. A., Bierkens, M. F. P., Lutz, A. F., and Immerzeel, W. W.: Impact of a global temperature rise of 1.5 degrees Celsius on Asia's glaciers, Nature, 549, 257-260, 10.1038/nature23878, 2017.

Kuipers Munneke, P., Reijmer, C. H., and van den Broeke, M. R.: Assessing the retrieval of cloud properties from radiation measurements over snow and ice, International Journal of Climatology, 31, 756-769, 10.1002/joc.2114, 2011.

Litt, M., Sicart, J. E., Helgason, W. D., and Wagnon, P.: Turbulence Characteristics in the Atmospheric Surface Layer for Different Wind Regimes over the Tropical Zongo Glacier (Bolivia,16² S), Boundary-Layer Meteorology, 154, 471-495, 10.1007/s10546-014-9975-6, 2014.

Litt, M., Shea, J., Wagnon, P., Steiner, J., Koch, I., Stigter, E., and Immerzeel, W.: Glacier ablation and temperature indexed melt models in the Nepalese Himalaya, Sci Rep, 9, 5264, 10.1038/s41598-019-41657-5, 2019.

MacDonell, S., Kinnard, C., Mölg, T., Nicholson, L., and Abermann, J.: Meteorological drivers of ablation processes on a cold 605 glacier in the semi-arid Andes of Chile, The Cryosphere, 7, 1513-1526, 10.5194/tc-7-1513-2013, 2013.

Mackintosh, A. N., Anderson, B. M., Lorrey, A. M., Renwick, J. A., Frei, P., and Dean, S. M.: Regional cooling caused recent New Zealand glacier advances in a period of global warming, Nature Communications, 8, 14202, 10.1038/ncomms14202, 2017.

Marzeion, B., Kaser, G., Maussion, F., and Champollion, N.: Limited influence of climate change mitigation on short-term glacier mass loss, Nature Climate Change, 8, 305-308, 10.1038/s41558-018-0093-1, 2018.

Mernild, S. H., Liston, G. E., and Hiemstra, C. A.: Northern Hemisphere Glacier and Ice Cap Surface Mass Balance and Contribution to Sea Level Rise, Journal of Climate, 27, 6051-6073, 10.1175/jcli-d-13-00669.1, 2014. 
https://doi.org/10.5194/tc-2022-24

Preprint. Discussion started: 17 February 2022

(c) Author(s) 2022. CC BY 4.0 License.

Mölg, T., Cullen, N. J., and Kaser, G.: Solar radiation, cloudiness and longwave radiation over low-latitude glaciers: implications for mass-balance modelling, Journal of Glaciology, 55, 292-302, 10.3189/002214309788608822, 2009a.

615 Mölg, T., Cullen, N. J., Hardy, D. R., Winkler, M., and Kaser, G.: Quantifying Climate Change in the Tropical Midtroposphere over East Africa from Glacier Shrinkage on Kilimanjaro, Journal of Climate, 22, 4162-4181, 10.1175/2009jcli2954.1, 2009b.

Mölg, T., Hardy, D. R., Collier, E., Kropač, E., Schmid, C., Cullen, N. J., Kaser, G., Prinz, R., and Winkler, M.: Mesoscale atmospheric circulation controls of local meteorological elevation gradients on Kersten Glacier near Kilimanjaro summit, Earth System Dynamics, 11, 653-672, 10.5194/esd-11-653-2020, 2020.

Oerlemans, J.: Extracting a climate signal from 169 glacier records, Science, 308, 675-677, 10.1126/science.1107046, 2005.

Oerlemans, J., Giesen, R. H., and van den Broeke, M. R.: Retreating alpine glaciers: increased melt rates due to accumulation of dust (Vadret da Morteratsch, Switzerland), Journal of Glaciology, 55, 729-736, 10.3189/002214309789470969, 2009.

Pellicciotti, F., Raschle, T., Huerlimann, T., Carenzo, M., and Burlando, P.: Transmission of solar radiation through clouds on melting glaciers: a comparison of parameterizations and their impact on melt modelling, Journal of Glaciology, 57, 367-381, 10.3189/002214311796406013, 2011.

Pellicciotti, F., Brock, B. W., Strasser, U., Burlando, P., Funk, M., and Corripio, J.: An enhanced temperature-index glacier melt model including the shortwave radiation balance: development and testing for Haut Glacier d'Arolla, Switzerland, Journal of Glaciology, 51, 573-587, 10.3189/172756505781829124, 2005.

Putnam, A. E., Schaefer, J. M., Denton, G. H., Barrell, D. J. A., Finkel, R. C., Andersen, B. G., Schwartz, R., Chinn, T. J. H., 630 and Doughty, A. M.: Regional climate control of glaciers in New Zealand and Europe during the pre-industrial Holocene, Nature Geoscience, 5, 627-630, 10.1038/ngeo1548, 2012.

Radić, V., Bliss, A., Beedlow, A. C., Hock, R., Miles, E., and Cogley, J. G.: Regional and global projections of twenty-first century glacier mass changes in response to climate scenarios from global climate models, Climate Dynamics, 42, 37-58, 10.1007/s00382-013-1719-7, 2014.

635 Sicart, J. E., Hock, R., and Six, D.: Glacier melt, air temperature, and energy balance in different climates: The Bolivian Tropics, the French Alps, and northern Sweden, Journal of Geophysical Research, 113, 10.1029/2008jd010406, 2008.

Sicart, J. E., Wagnon, P., and Ribstein, P.: Atmospheric controls of the heat balance of Zongo Glacier (16 ${ }^{\circ}$ S, Bolivia), Journal of Geophysical Research, 110, 10.1029/2004jd005732, 2005.

Sicart, J. E., Espinoza, J. C., Quéno, L., and Medina, M.: Radiative properties of clouds over a tropical Bolivian glacier:

640 seasonal variations and relationship with regional atmospheric circulation, International Journal of Climatology, 36, 31163128, 10.1002/joc.4540, 2016.

Sicart, J. E., Pomeroy, J. W., Essery, R. L. H., and Bewley, D.: Incoming longwave radiation to melting snow: observations, sensitivity and estimation in Northern environments, Hydrological Processes, 20, 3697-3708, 10.1002/hyp.6383, 2006.

van den Broeke, M. R., Smeets, C. J. P. P., and van de Wal, R. S. W.: The seasonal cycle and interannual variability of surface

645 energy balance and melt in the ablation zone of the west Greenland ice sheet, The Cryosphere, 5, 377-390, 10.5194/tc-5-3772011, 2011.

Van Tricht, K., Lhermitte, S., Lenaerts, J. T., Gorodetskaya, I. V., L'Ecuyer, T. S., Noel, B., van den Broeke, M. R., Turner, D. D., and van Lipzig, N. P.: Clouds enhance Greenland ice sheet meltwater runoff, Nature Communications, 7, 10266, 10.1038/ncomms10266, 2016.

650 Zekollari, H., Huss, M., and Farinotti, D.: Modelling the future evolution of glaciers in the European Alps under the EUROCORDEX RCM ensemble, The Cryosphere, 13, 1125-1146, 10.5194/tc-13-1125-2019, 2019.

Zemp, M., Huss, M., Thibert, E., Eckert, N., McNabb, R., Huber, J., Barandun, M., Machguth, H., Nussbaumer, S. U., GartnerRoer, I., Thomson, L., Paul, F., Maussion, F., Kutuzov, S., and Cogley, J. G.: Global glacier mass changes and their contributions to sea-level rise from 1961 to 2016, Nature, 568, 382-386, 10.1038/s41586-019-1071-0, 2019. 
https://doi.org/10.5194/tc-2022-24

Preprint. Discussion started: 17 February 2022

(C) Author(s) 2022. CC BY 4.0 License.

655 Appendix:

Table A1: Optimised clear-sky emissivity coefficients and error in $\varepsilon_{\mathrm{cs}}$.

\begin{tabular}{ccc}
\hline Site & $\begin{array}{c}\text { Fitted } \\
\text { value of } b\end{array}$ & $\begin{array}{c}\text { Root-mean squares error of } \\
\text { calculated } \varepsilon_{\mathrm{cs}} \text { vs } \varepsilon_{\text {eff }} \text { in selected } \\
\text { clear-sky conditions }\end{array}$ \\
\hline BREW & 0.443 & 0.0190 \\
CHHO & 0.538 & 0.0280 \\
CABL & 0.483 & 0.0199 \\
CACC & 0.436 & 0.0190 \\
GUAN & 0.379 & 0.0292 \\
KERS & 0.291 & 0.0236 \\
LANG & 0.458 & 0.0201 \\
MERA & 0.472 & 0.0391 \\
MIDT & 0.428 & 0.0166 \\
MORT & 0.398 & 0.0240 \\
NAUL & 0.495 & 0.0378 \\
NORD & 0.489 & 0.0202 \\
QASI & 0.466 & 0.0124 \\
STOR & 0.463 & 0.0171 \\
YALA & 0.468 & 0.0240 \\
ZONG & 0.443 & 0.0251 \\
\hline
\end{tabular}


https://doi.org/10.5194/tc-2022-24

Preprint. Discussion started: 17 February 2022

(c) Author(s) 2022. CC BY 4.0 License.
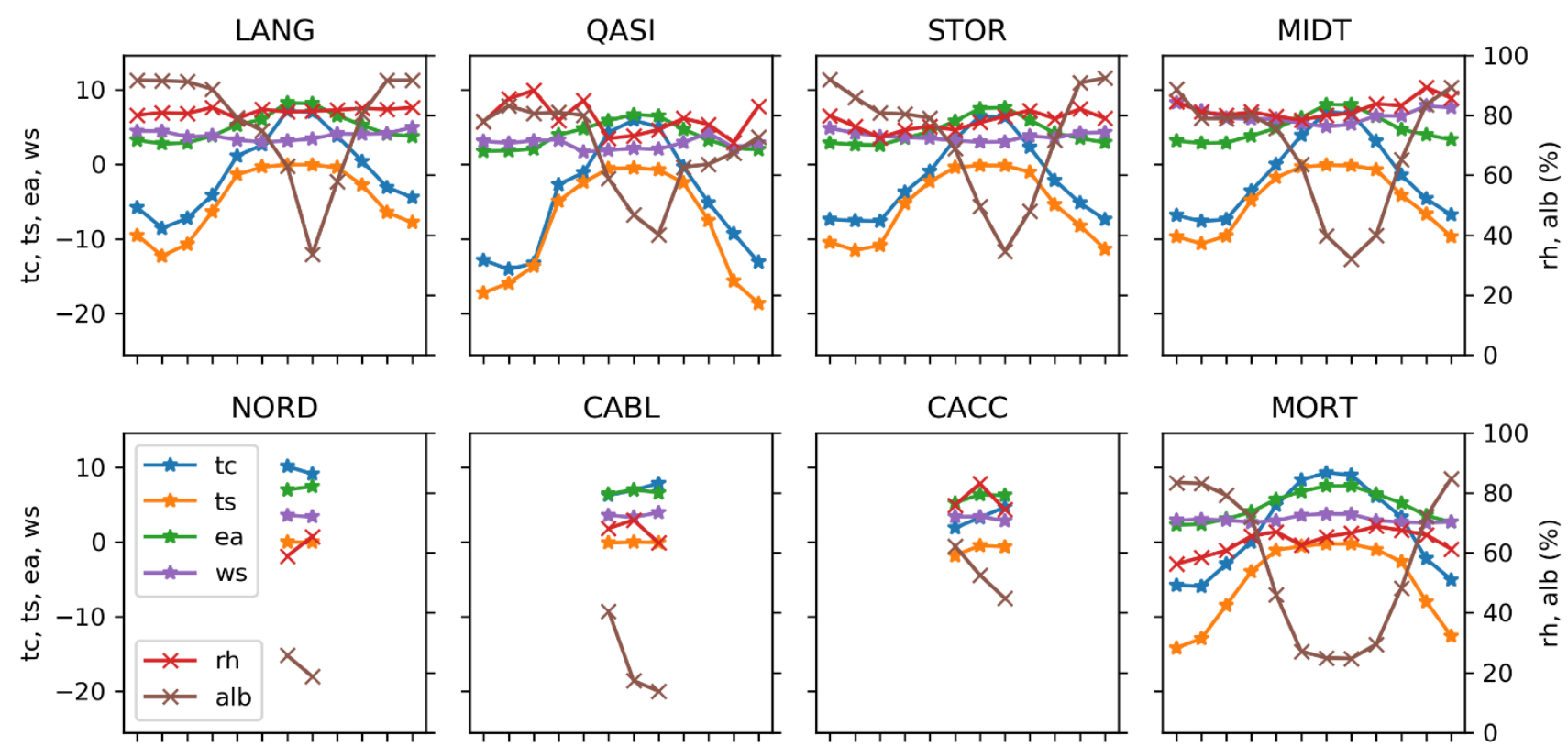

CABL

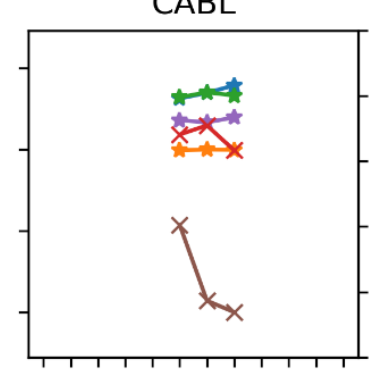

CACC
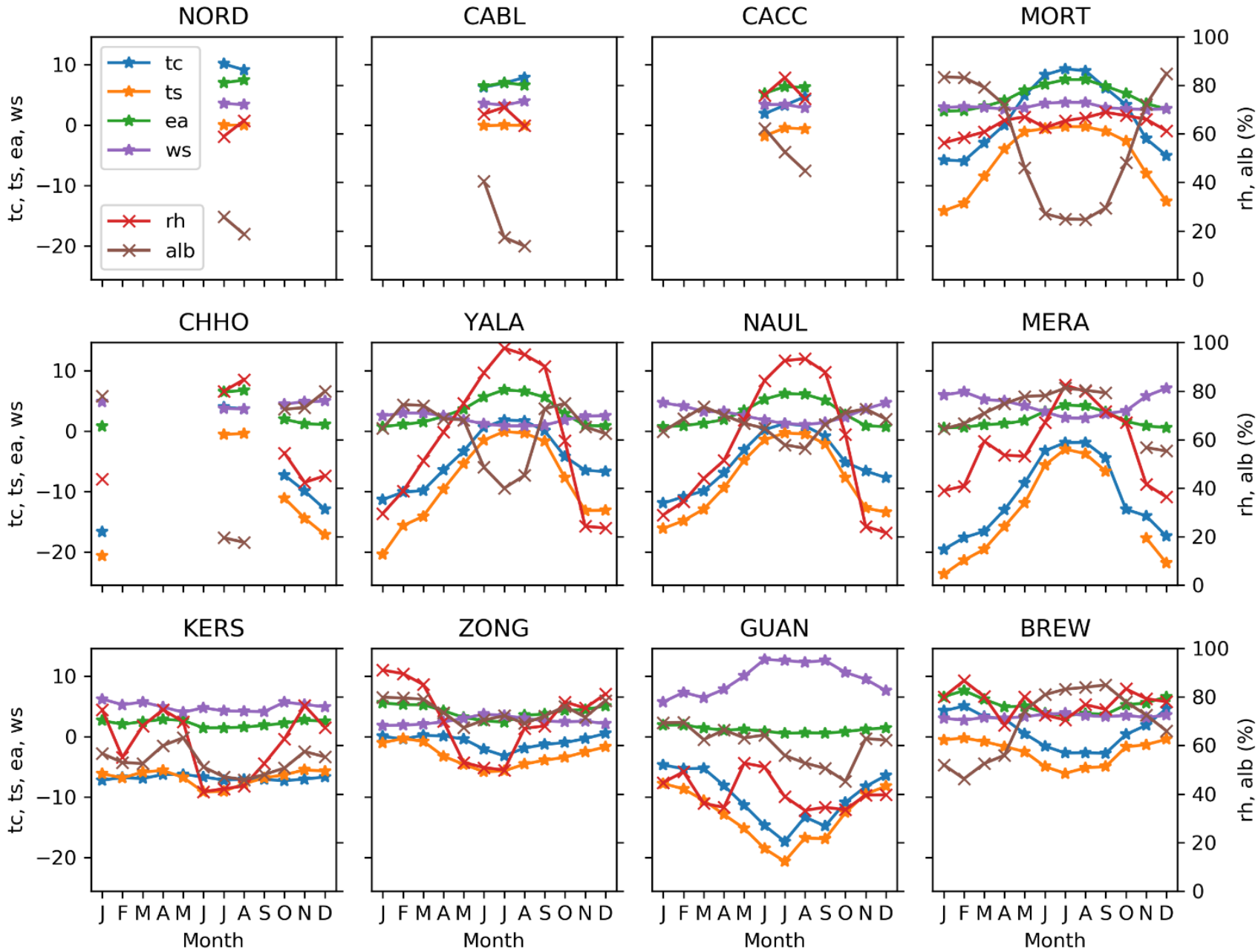

Figure A1: Monthly average near-surface meteorological conditions at each site. Note monthly value only shown for a site if $>10$ complete days in month across full record. 
https://doi.org/10.5194/tc-2022-24

Preprint. Discussion started: 17 February 2022

(c) Author(s) 2022. CC BY 4.0 License.

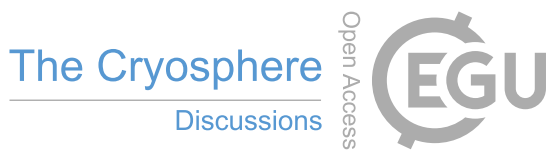
(c) (1)
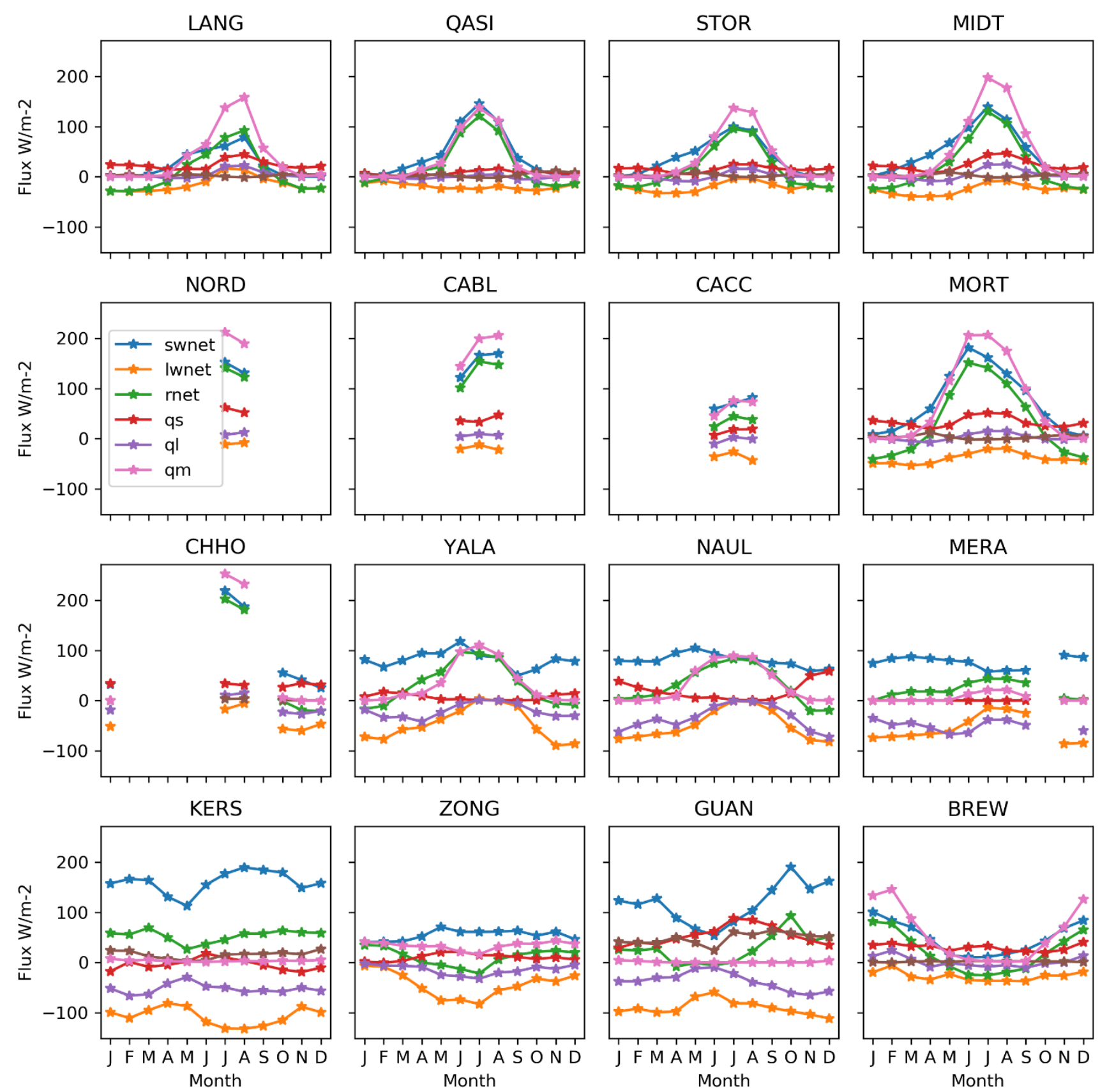

Figure A2: Monthly average SEB fluxes at each site. Note monthly value only shown for a site if > 10 complete days in month across full record. 

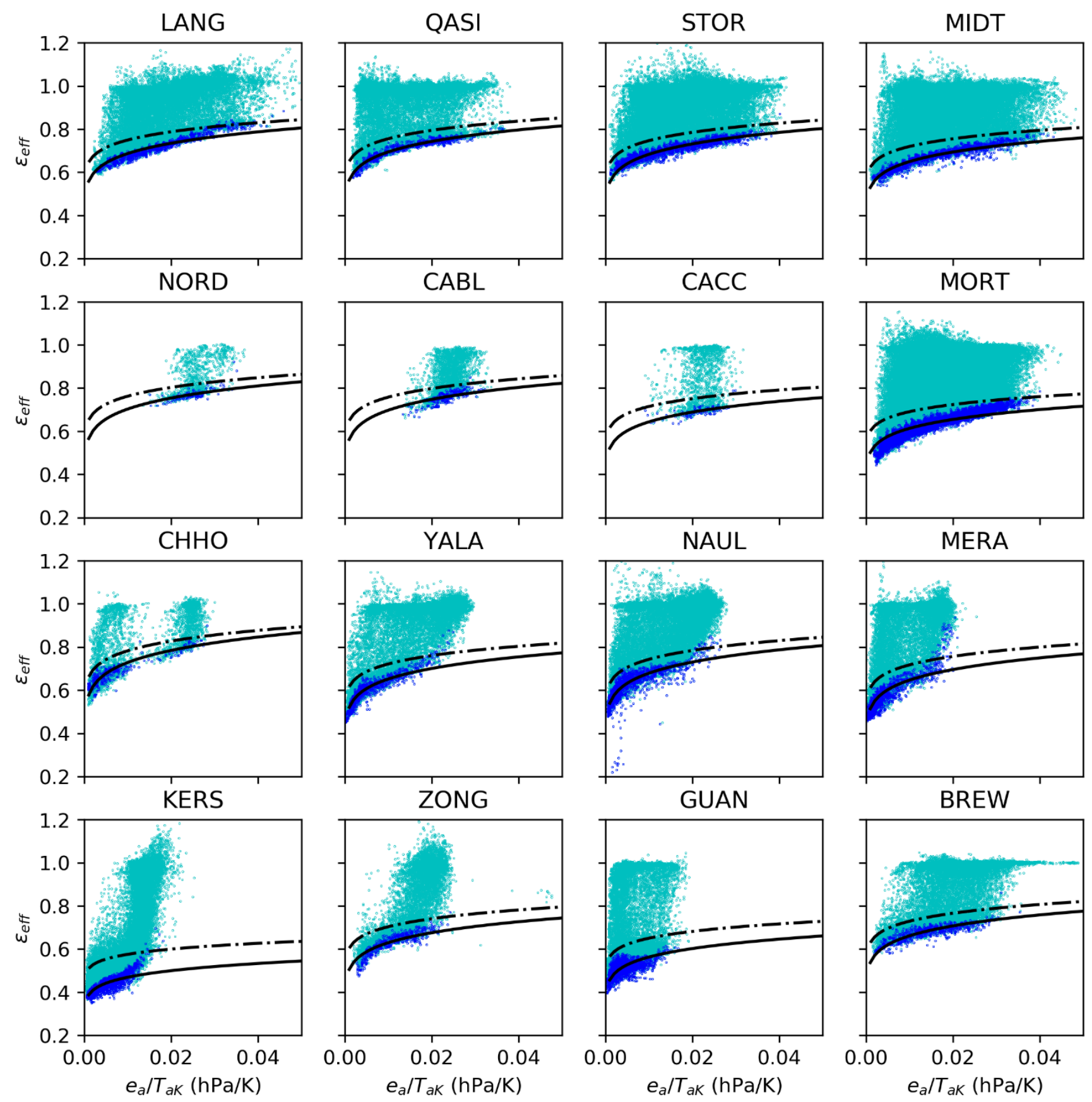

Figure A3: Observed $\varepsilon_{e f f}$ (points) and calculated $\varepsilon_{c s}$ (solid line) fitted to lowest $10 \%$ of $L$ Win in $30 e_{a} / T_{a . K}$ bins (shown in blue). Calculated $\varepsilon_{e f f}$ at clear-sky limit of $N_{\varepsilon}=0.2$ (dash-dotted line). 
https://doi.org/10.5194/tc-2022-24

Preprint. Discussion started: 17 February 2022

(c) Author(s) 2022. CC BY 4.0 License.
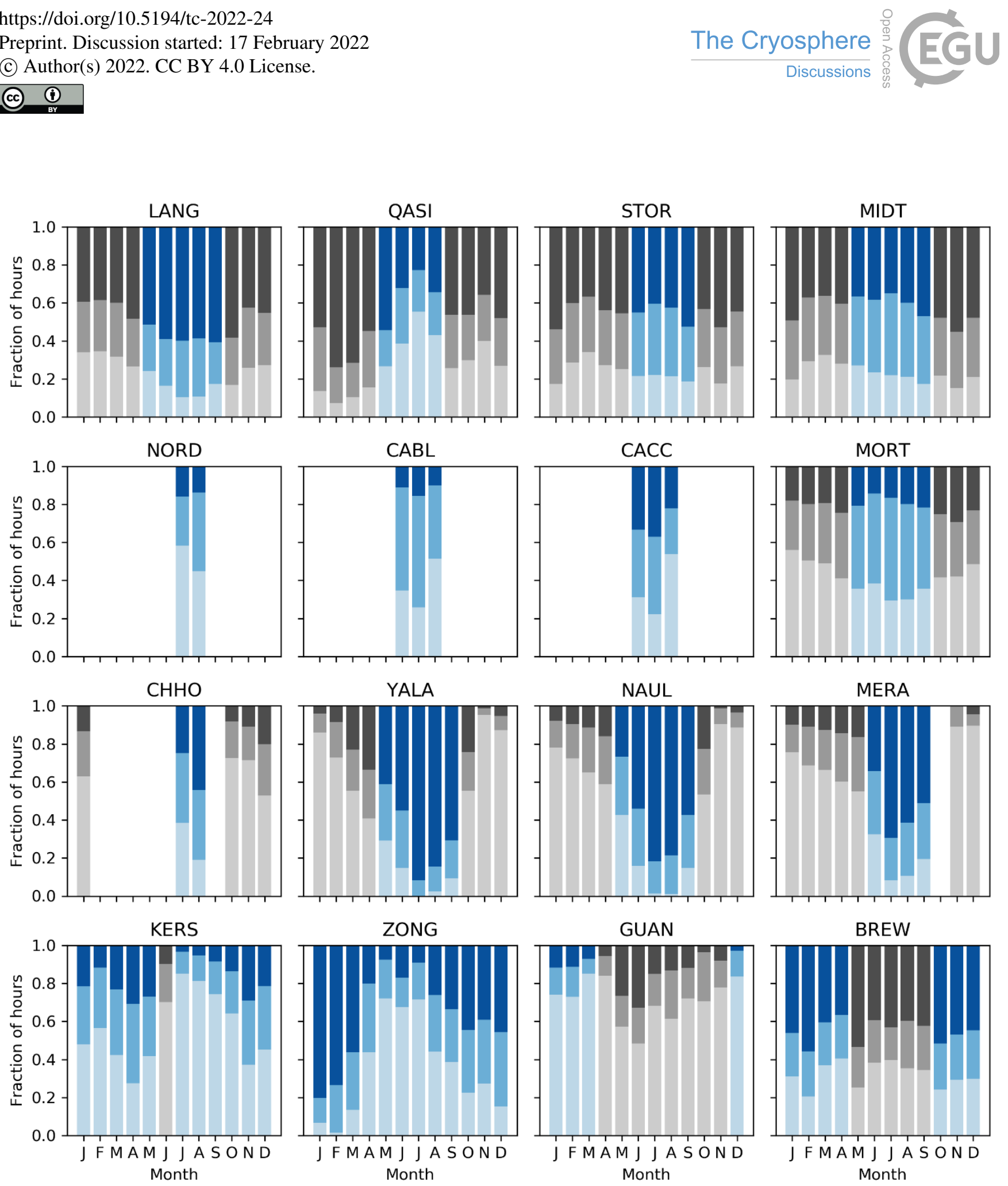

Figure A4: Monthly fraction of clear-sky, partial-cloud and overcast conditions defined using hourly cloudiness $\left(N_{\varepsilon}\right)$. 
https://doi.org/10.5194/tc-2022-24

Preprint. Discussion started: 17 February 2022

(c) Author(s) 2022. CC BY 4.0 License.

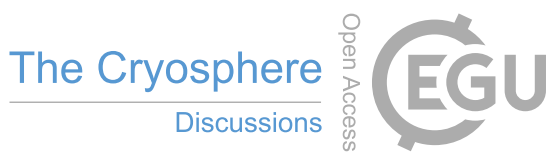

(c) (i)

(a) SWnet

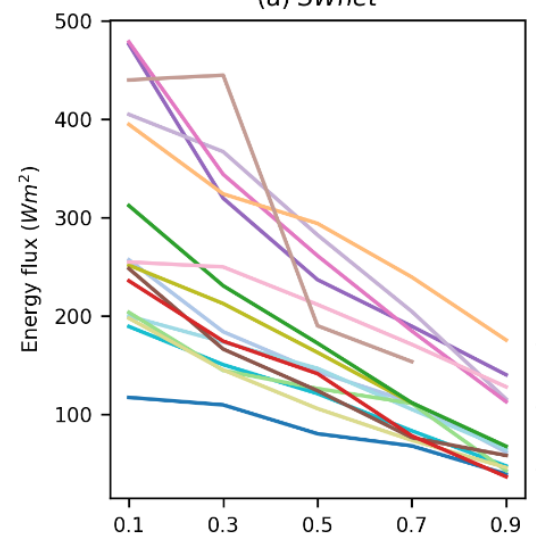

(d) $Q_{S}$

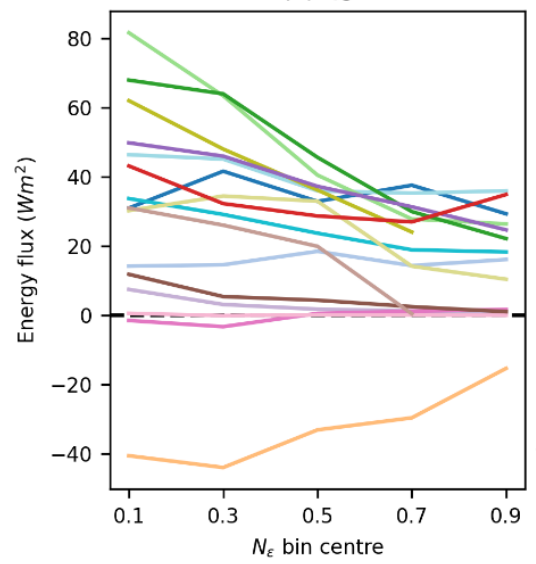

(b) LWnet

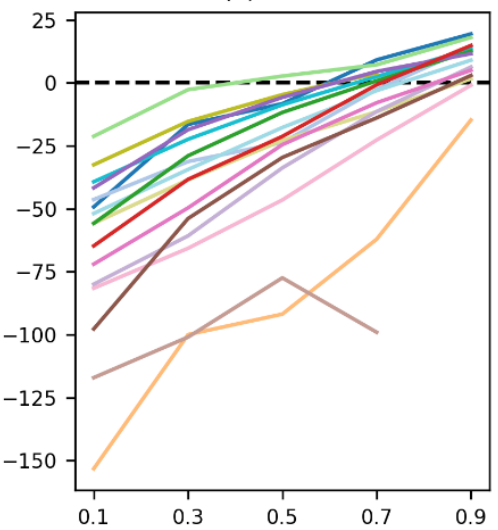

(e) $Q_{L}$

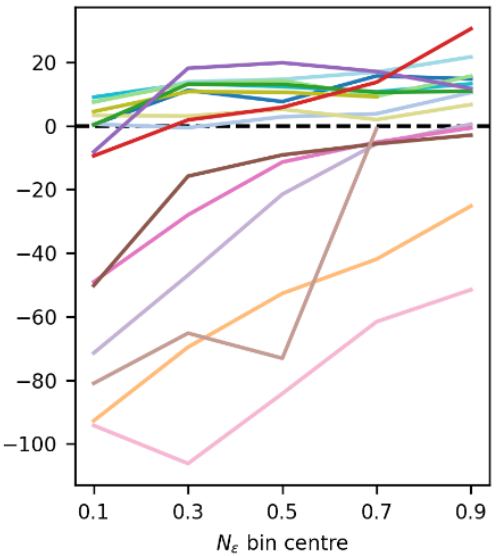

(c) Rnet

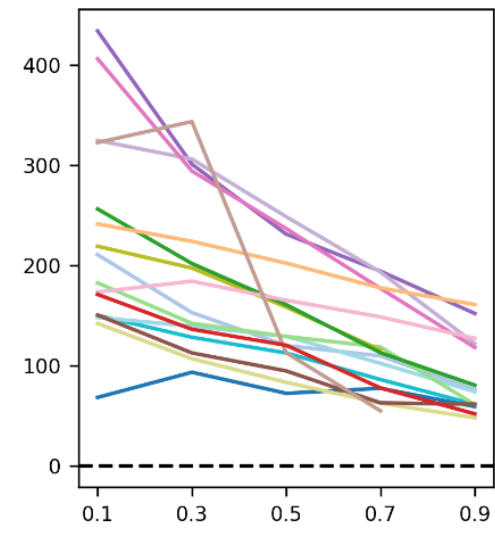

(f) $L W n e t+Q_{S}+Q_{L}$

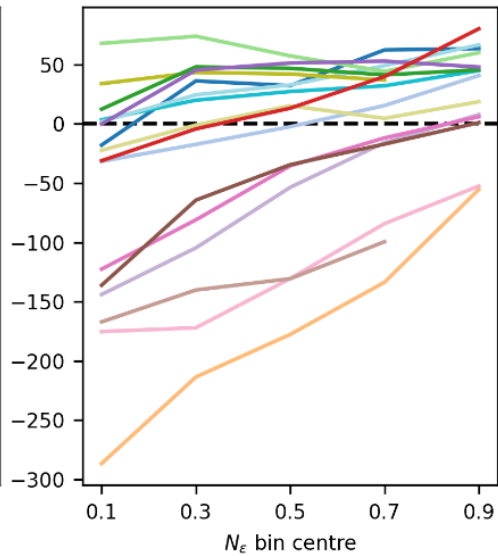

Figure A5: Average melt season SEB terms during hours with surface melt for different cloud conditions $\left(N_{\varepsilon}\right)$. 

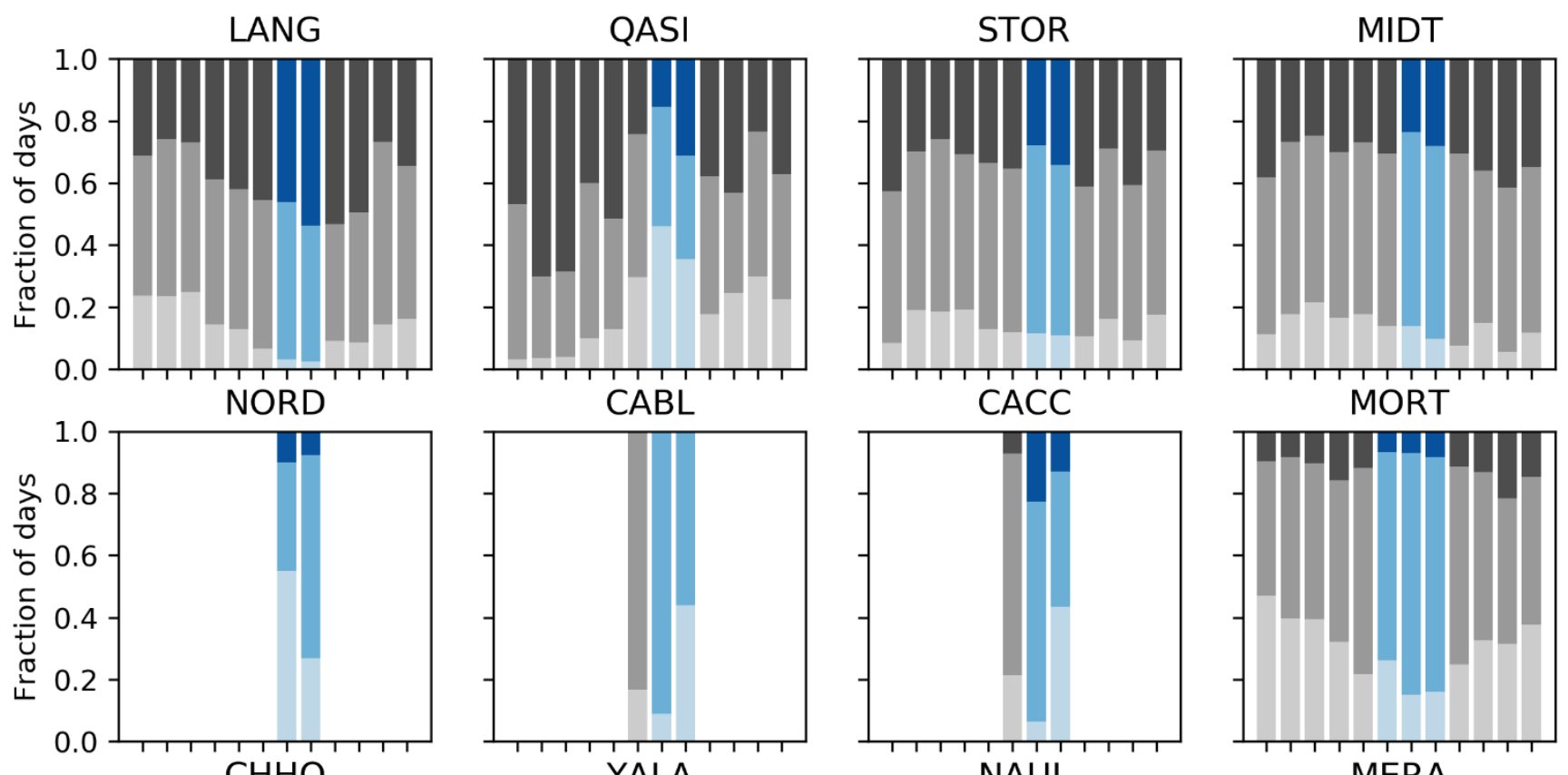

CACC
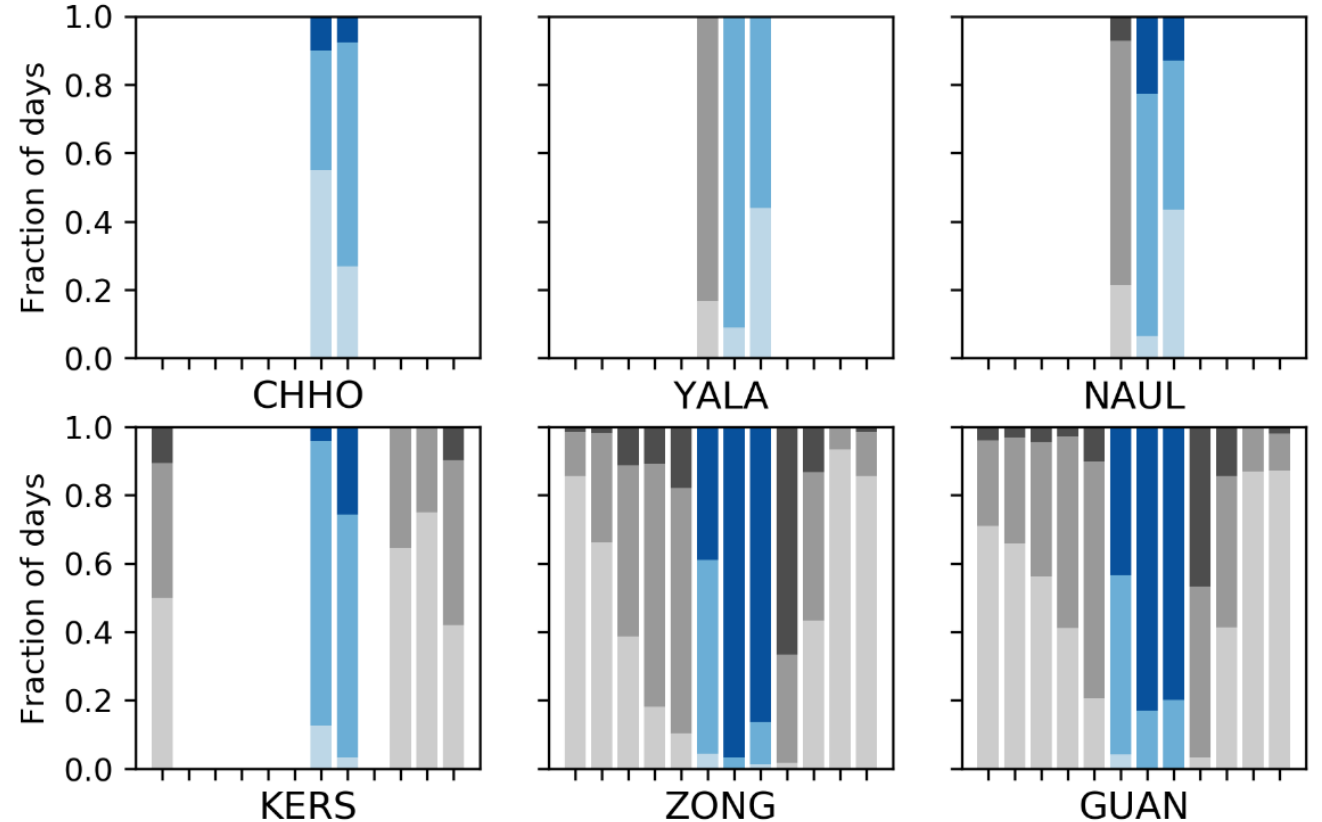

MORT

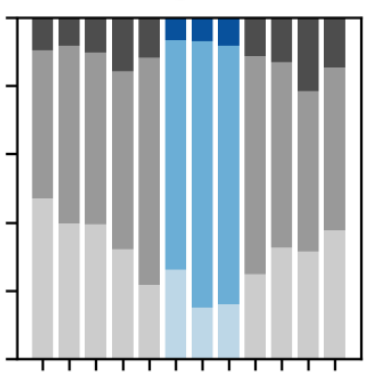

NAUL

MERA
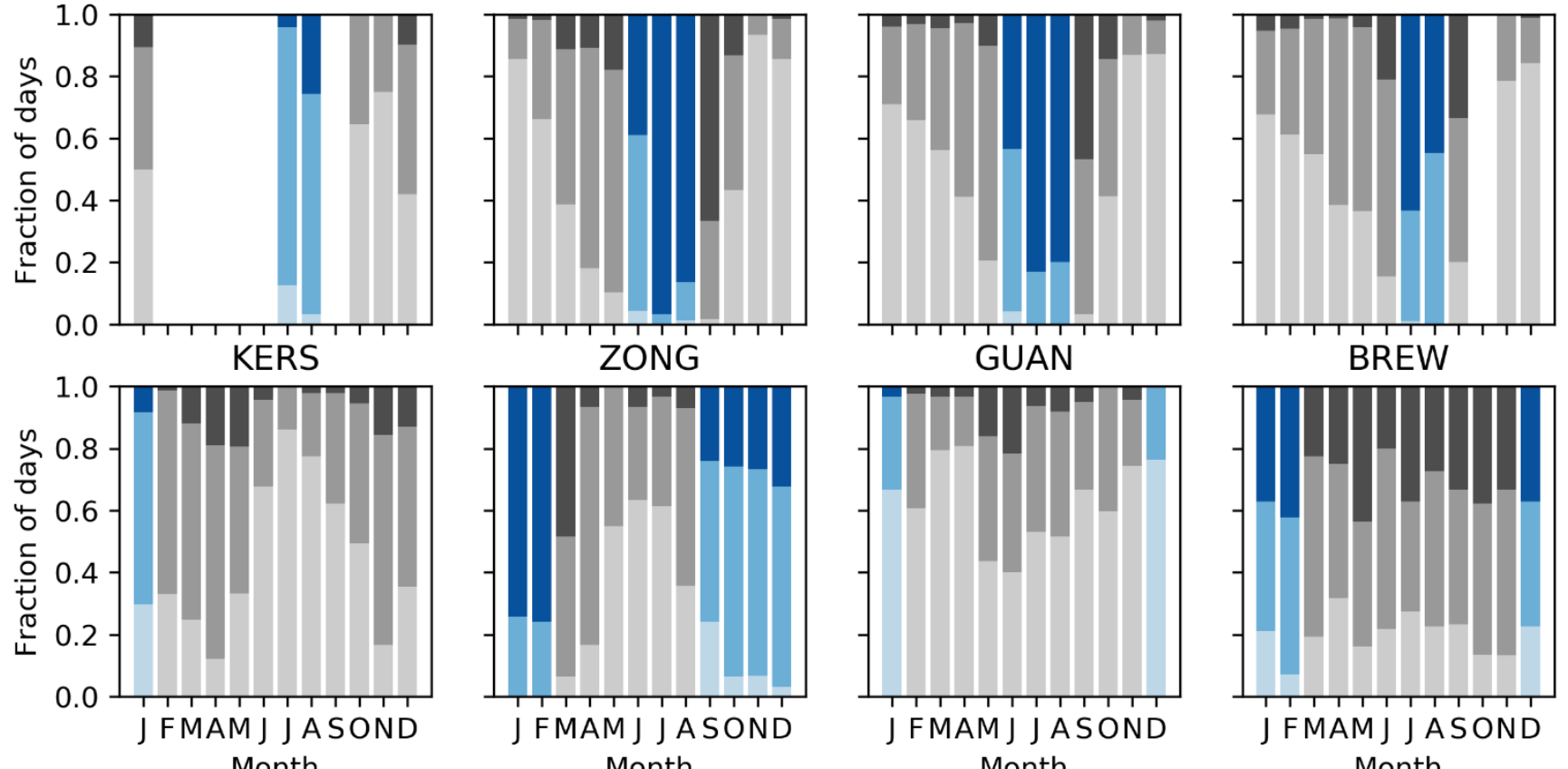

Month
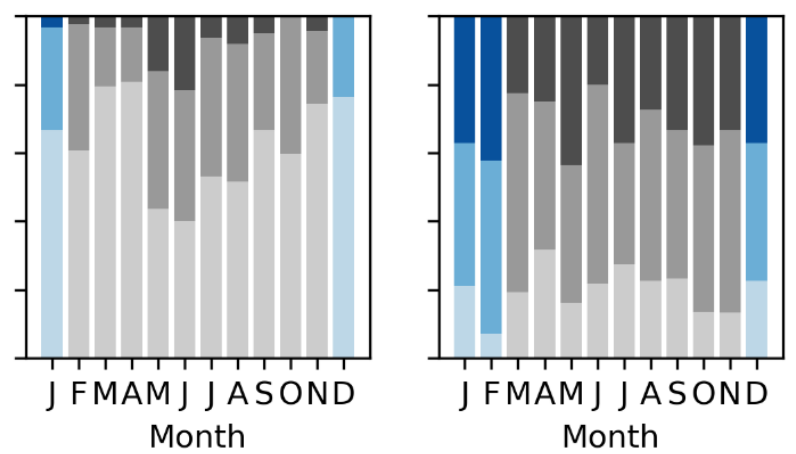

Figure A6: As for Figure 5 but showing months selected with $>80 \%$ of maximum monthly-average $Q_{M}$. 